This article has been accepted for publication in Geophysical Journal International (C: The Author(s) 2019. Published by Oxford University Press on behalf of The Royal Astronomical Society.

Savidge, E., Nissen, E., Nemati, M., Karasözen, E., Hollingsworth, J., Talebian, M., Bergman, E., Ghods, A., Ghorashi, M., Kosari, E., Rashidi, A., Rashidi, A. (2019): The December 2017 Hojedk (Iran) earthquake triplet- sequential rupture of shallow reverse faults in a strike-slip restraining bend. - Geophysical Journal International, 217, 2, 909925. https://doi.org/10.1093/gji/ggz053 


\title{
The December 2017 Hojedk (Iran) earthquake triplet—sequential rupture of shallow reverse faults in a strike-slip restraining bend
}

\author{
Elena Savidge, ${ }^{1}$ Edwin Nissen, ${ }^{1}$ Majid Nemati, ${ }^{2}$ Ezgi Karasözen, ${ }^{3}$ James Hollingsworth, ${ }^{4}$ \\ Morteza Talebian, ${ }^{5}$ Eric Bergman, ${ }^{6}$ Abdolreza Ghods, ${ }^{7}$ Manouchehr Ghorashi, ${ }^{5}$ \\ Ehsan Kosari, ${ }^{5,8}$ Ahmad Rashidi ${ }^{9,10}$ and Ali Rashidi ${ }^{10}$ \\ ${ }^{1}$ School of Earth and Ocean Sciences, University of Victoria, Victoria, BC V8P 3E6, Canada. E-mail:enissen@uvic.ca \\ ${ }^{2}$ Department of Geology and Earthquake Research Center, Shahid Bahonar University of Kerman, Kerman, Iran. \\ ${ }^{3}$ Department of Geophysics, Colorado School of Mines, 1500 Illinois St, Golden, CO 80401, USA \\ ${ }^{4}$ Université Grenoble Alpes, Université Savoie Mont Blanc, CNRS, IRD, IFSTTAR, ISTerre, 38000 Grenoble, France \\ ${ }^{5}$ Research Institute for Earth Sciences, Geological Survey of Iran, Tehran, Iran \\ ${ }^{6}$ Global Seismological Services, Golden, CO 80401, USA \\ ${ }^{7}$ Department of Earth Sciences, Institute for Advanced Studies in Basic Sciences, University of Zanjan, Zanjan, Iran \\ ${ }^{8}$ Helmholtz Centre Potsdam, GFZ German Research Centre for Geosciences, Potsdam 14473, Germany \\ ${ }^{9}$ International Institute of Earthquake Engineering and Seismology, Tehran, Iran \\ ${ }^{10}$ Geological Survey of Iran, Kerman Branch, Kerman, Iran
}

Accepted 2019 January 29. Received 2019 January 14; in original form 2018 August 18

\begin{abstract}
SUMMAR Y
A triplet of $M_{\mathrm{W}} \sim 6$ earthquakes on 2017 December 1-12 occurred $\sim 50 \mathrm{~km}$ north of Kerman, Iran, in an area of mountainous topography where several major right-lateral strike-slip fault systems - the Gowk, Nayband, Lakar Kuh and Kuh Banan faults - converge. Here we assess their source parameters and surficial expression using regional and teleseismic waveforms and arrival times, synthetic aperture radar interferometry, optical satellite image correlation and field observations. All three main shocks occurred on shallow reverse faults associated with the southern termination of the Lakar Kuh right-lateral strike-slip fault. The first two main shocks on 1 December and 12 December (08:43 UTC) likely ruptured and reruptured a previously unrecognized, blind, NE-dipping fault beneath the Mian Kuh range. Slip in both earthquakes extends much further along strike than down dip, hinting at structural or stratigraphic controls on rupture dimensions. The third main shock on 12 December (21:41 UTC) is perhaps the most interesting of the three events. It ruptured a conjugate SW-dipping thrust in the hangingwall of the first fault, generating a sinuous fault scarp in the alluvial plain north of the Mian Kuh range, consistent with its unusually shallow centroid depth of $\sim 2 \mathrm{~km}$. Its high ratio of net surface slip (average $\sim 1.5 \mathrm{~m}$ and maximum $\sim 2.5 \mathrm{~m}$ ) to length $(\sim 7 \mathrm{~km})$ and its narrow down-dip width $(\sim 6 \mathrm{~km})$ implies a very high stress drop. The surface rupture aligns along-strike with larger scarps that contain uplifted and incised fan surfaces in their hangingwalls, but this subtle expression of active faulting had not been fully recognized prior to these earthquakes. The clustering in space and time of large, shallow earthquakes on hidden faults is of broad concern for seismic hazard assessment in mountainous parts of Iran and in other collisional settings.
\end{abstract}

Key words: Satellite geodesy; Earthquake hazards; Earthquake source observations; Seismicity and tectonics; Continental neotectonics.

\section{INTRODUCTION}

The active tectonics of eastern Iran are governed by regional $\sim$ NNEoriented convergence between the Arabian and Eurasian plates and associated right-lateral shear between central Iran and Afghanistan [Fig. 1a; Vernant et al. (e.g. 2004)]. Most of the seismic deformation is accommodated along large $\mathrm{N}-\mathrm{S}$ to $\mathrm{NW}-\mathrm{SE}$-trending right-lateral strike-slip faults (Jackson \& McKenzie 1984; Berberian \& Yeats 1999; Walker \& Jackson 2004). Of the major right-lateral structures, the Gowk fault zone has been particularly active in recent decades, hosting destructive earthquakes at $\operatorname{Sirch}\left(M_{\mathrm{w}} 7.1\right)$ and Golbaf $\left(M_{\mathrm{w}}\right.$ 6.6) in 1981 and at Fandoqa $\left(M_{\mathrm{w}} 6.6\right)$ in 1998 (Berberian et al. 2001). North of the Gowk fault, the Nayband and Lakar Kuh faults have experienced relatively little instrumental or historical seismicity, 

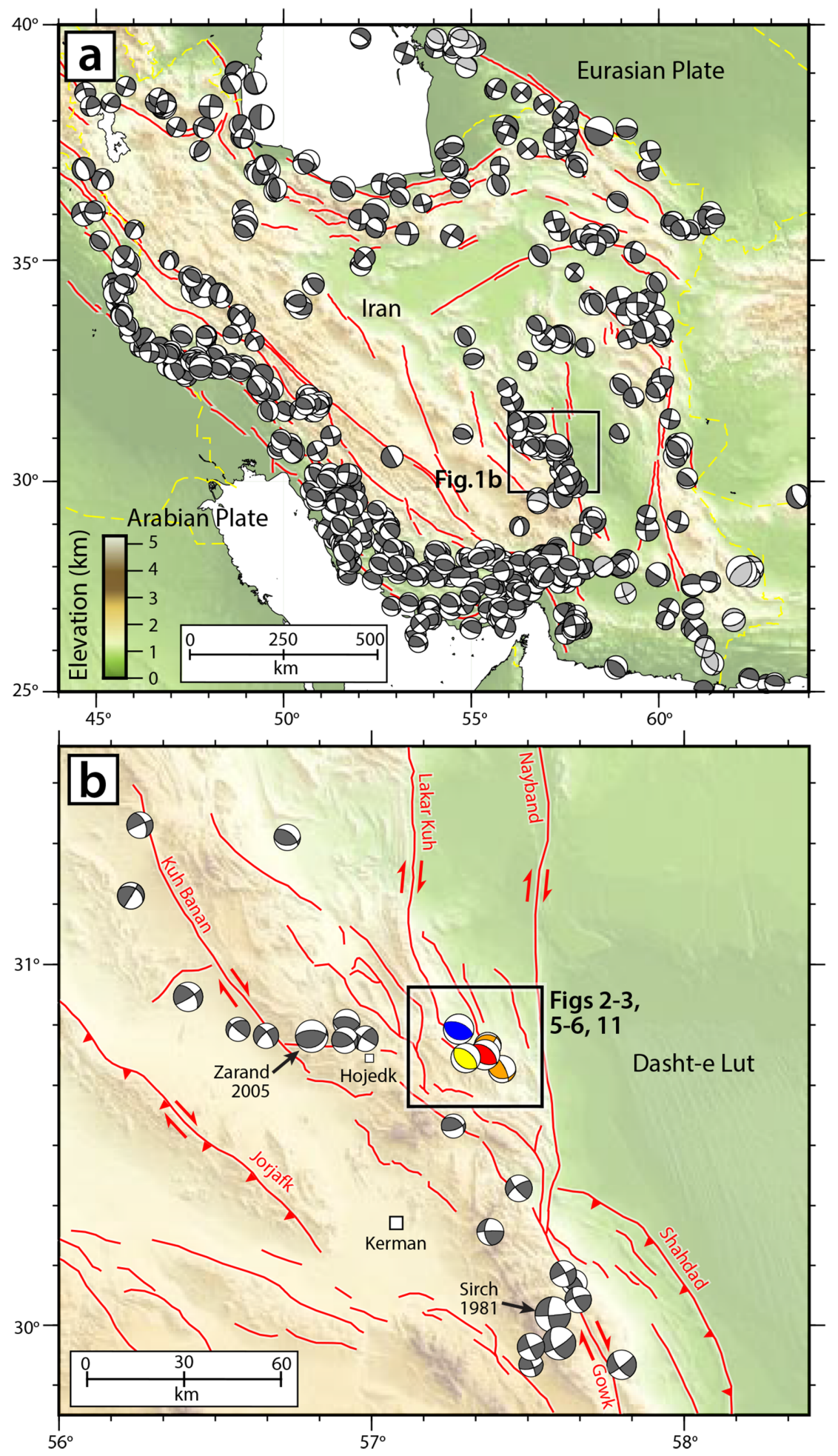

Figure 1. (a) Major active faults (red) and earthquake focal mechanisms of Iran. Shallow earthquakes ( $<30 \mathrm{~km}$ centroid depths) are in dark grey while deeper earthquakes, including intraslab events associated with the Makran subduction zone, are in light grey; depths are from body waveform modelling studies where available, or otherwise the GCMT catalogue. (b) Enlarged map of the Kerman region showing background earthquake focal mechanisms in dark grey and those of the 2017 December Hojedk sequence in colour (E1 in blue, E2 in yellow, E3 in red and smaller aftershocks in orange). Active faults are from Walker (2006) and Walker et al. (2010).

while the Kuh Banan fault is associated with just a few moderatesized instrumental events (Fig. 1b). The most destructive earthquake in the vicinity of these latter faults was the $2005 M_{\mathrm{w}} 6.4$ Zarand earthquake, which occurred on a previously unrecognized reverse fault east of and oblique to the Kuh Banan fault (Talebian et al. 2006; Nemati \& Gheitanchi 2011).

On 2017 December 1st at 02:32 UTC and 2017 December 12th at 08:43 and 21:41 UTC, three earthquakes with moment 
magnitudes $\left(M_{\mathrm{w}}\right) \sim 6$ and predominantly reverse faulting mechanisms occurred east of the village of Hojedk (Fig. 1b). With no easy geographical distinction, we simply call these events E1, E2 and E3, respectively. Several major active fault systems - including the Nayband, Gowk, Shahdad, Kuh Banan and Lakar Kuh faultsconverge in this area. Though the December 2017 earthquakes were not destructive - owing to the sparse population in this remote region - they may offer important insights into the structure and development of this major restraining bend, which impinges upon much larger settlements, most notably Kerman (population $\sim 800000$ ). Detailed geomorphological studies of active faulting in this area have been undertaken previously (Walker et al. 2010) and yet we will show that the three Hojedk earthquakes occurred on faults which had not previously been recognized. This has wider implications for seismic hazard in and adjacent to mountainous parts of Iran and in other continental collision zones. Finally, the close spatial and temporal clustering of three approximately evenly sized events is also unusual (e.g. Nemati 2014) and of interest.

The goals of this paper are to evaluate the faults responsible for the Hojedk earthquakes and assess their link with regional topography, geomorphology and geological structure. We begin by using regional and teleseismic arrival times, first motions, and waveforms to determine epicentres and focal mechanisms within the sequence (Section 2). Next, we use Interferometric Synthetic Aperture Radar (InSAR) to establish the fault geometries and slip distributions of the three main shocks (Section 3). A clear surface rupture generated by the third main shock (E3) is characterized using optical satellite image correlation and field measurements (Section 4). Finally, we synthesize these diverse observations and discuss broader implications of the Hojedk sequence for regional tectonics and seismic hazard (Section 5).

\section{EARTHQUAKE LOCATIONS AND FOCAL MECHANISMS FROM SEISM OLOGY}

\subsection{Calibrated earthquake relocations}

We used the multiple-earthquake relocation technique Mloc (Bergman \& Solomon 1990; Walker et al. 2011; Karasözen et al. 2016) to relocate epicentres of the three main shocks, 43 wellrecorded aftershocks up to mid-January 2018, and 88 background events from the period 2005 February to 2017 September, including many belonging to the 2005 Zarand sequence (Talebian et al. 2006). When appropriate data sets are available, Mloc can obtain 'calibrated' locations in which bias from unknown Earth structure is minimized. Mloc adopts the Hypocentroidal Decomposition approach (Jordan \& Sverdrup 1981) of separating the relocation procedure into two distinct inverse problems, allowing phase arrival time data to be tailored to each step (e.g. Ghods et al. 2012; Elliott et al. 2015; Karasözen et al. 2016, 2018; Nissen et al. 2019). In the first step, we calculated cluster vectors that describe the relative location and origin time of each individual event with respect to the geometrical mean of all events, known as the hypocentroid. Since this calculation is based on traveltime differences, we used arrival times of all phases recorded at all distances, collated from both regional bulletins (the Building and House Research Center, BHRC; the Iranian Seismological Center, IRSC; the International Institute of Earthquake Engineering and Seismology, IIEES) and global archives (the International Seismological Centre, ISC; the
USGS National Earthquake Information Center, NEIC). In the second step, we determined the absolute location and origin time of the hypocentroid, which added to the cluster vectors establishes the absolute coordinates of all events. Here, we restricted the data set to direct $P g$ and $S g$ phases at epicentral distances $<2^{\circ}$, the shortest distance range for which good azimuthal coverage could still be achieved (Supporting Information Fig. S1). Limited to such short ray paths, biases from unknown velocity structure are thus minimized, yielding truly calibrated hypocentres (latitude, longitude, focal depth, origin time and their uncertainties).

By analysing fits to $P g$ and $P n$ at the closest stations and $P n$ and $S n$ at regional distances, we settled upon a two-layered crustal velocity model with $V_{P} 5.8 \mathrm{~km} \mathrm{~s}^{-1}$ and $V_{S} 3.45 \mathrm{~km} \mathrm{~s}^{-1}$ for the upper $15 \mathrm{~km}$ and $V_{P} 6.1 \mathrm{~km} \mathrm{~s}^{-1}$ and $V_{S} 3.55 \mathrm{~km} \mathrm{~s}^{-1}$ from $15 \mathrm{~km}$ to the Moho at $40 \mathrm{~km}$. Below the Moho, we used velocities from the ak135 1-D Earth model (Kennett et al. 1995). Since no near-source data were available within $\sim 0.25^{\circ}$ of the Hojedk earthquakes (Supporting Information Fig. S1), hypocentre depths were set manually by minimizing residuals at the closest stations.

Relocated seismicity is shown in Fig. 2 and tabulated in Supporting Information Table S1, with shifts between initial and final locations and fits between observed phase arrivals and theoretical traveltimes provided in Supporting Information Figs S2 and S3, respectively. Calibrated epicentral uncertainties are all $<3 \mathrm{~km}$ at the 90 per cent confidence level; true location uncertainties are somewhat larger, since these formal values do not account for potential errors in velocity structure. Limited by the absence of near-source data, uncertainties in focal depth are estimated conservatively at $\pm 5 \mathrm{~km}$. Nevertheless, our estimated focal depths of $6-14 \mathrm{~km} \mathrm{lie}$ within the 5-20 km range in centroid depths of large central Iranian earthquakes determined previously (Baker 1993; Berberian et al. 2001; Walker et al. 2003; Talebian et al. 2006), lending confidence in our overall focal depth distribution.

The first two main shocks initiated close to the northern flank of the Mian Kuh mountains - the rugged northeastern limb of the large Gazk syncline - with the E2 epicentre $\sim 6 \mathrm{~km}$ west of E1 (Figs 2 and $3 \mathrm{~b}$ ). The third main shock, E3, initiated $\sim 9 \mathrm{~km}$ north of E2 in the unnamed low-relief basin north of Mian Kuh. Published centroid locations from the Global Centroid Moment Tensor (GCMT) project each lie $\sim 20 \mathrm{~km} \mathrm{SW}$ of the relocated epicentres, while U.S. Geological Survey (USGS) catalogue epicentres are shown to be significantly more accurate, within $\sim 5 \mathrm{~km}$ of our calibrated epicentres but with no systematic azimuthal bias (Fig. 3b).

Aftershocks form a diffuse cloud surrounding the main shocks and seem to lack clear lineaments that could indicate fault trends (Fig. 2). Furthermore, the limited focal depth resolution precludes us from identifying gradients in focal depth that might indicate fault dip directions. Nevertheless, there are some interesting temporal trends in the seismicity. E1 and most of the early aftershocks lie in the southeastern part of the seismicity zone, with E2 lying west of it. Early aftershocks of E2 are clustered north of it. E3 nucleates close to the E2 aftershocks, as well as some earlier E1 aftershocks. Seismicity following E3 then expands the aftershock zone further to the west and north.

\subsection{Main shock focal mechanisms from body waveform modelling}

We determined focal mechanisms for the three main shocks by modelling long-period teleseismic body waveforms, using a procedure (Molnar \& Lyon-Caen 1989) that has been applied almost 


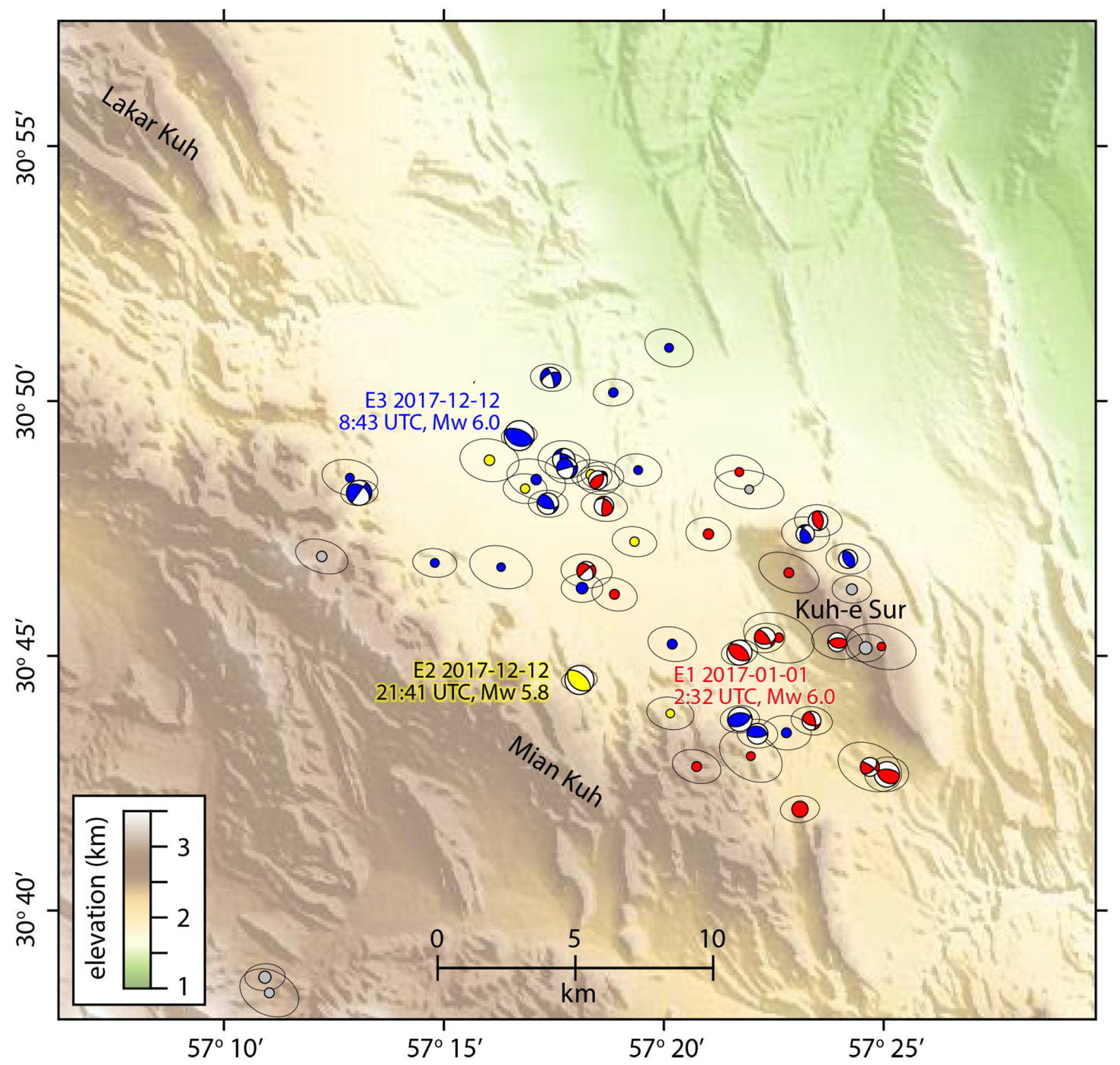

Figure 2. Relocated earthquake epicentres with 90 percent confidence ellipses, focal mechanisms of main shocks E1, E2 and E3 from body waveform modelling, and focal mechanisms of 16 aftershocks from first motion polarities and two additional aftershocks from the GCMT catalogue. Main shocks and aftershocks are coloured in sequence: E1 and early aftershocks preceding E2 are in red; E2 and its aftershocks preceding E3 are in yellow; and E3 and later aftershocks are in blue. Scattered seismicity preceding the December 2017 sequence is in grey.

routinely to moderate-to-large magnitude earthquakes in Iran; notable compilations include those of Priestley et al. (1994), Maggi et al. (2000), Talebian \& Jackson (2004), Nissen et al. (2011) and Penney et al. (2017). We used waveforms in the distance range $30^{\circ}-80^{\circ}$, thus avoiding complications from Earth's crust and outer core. These were bandpass filtered to periods of 15-100 s, such that the earthquakes can be modelled as simple point sources insensitive to heterogeneities in local velocity structure and fault slip. We used the MT5 version (Zwick et al. 1994) of the weighted least squares algorithm of McCaffrey \& Abers (1988) and McCaffrey et al. (1991) to minimize residuals between observed waveforms and synthetic seismograms computed for a point source embedded within an elastic half-space (using $V_{P} 6 \mathrm{~km} \mathrm{~s}^{-1}, V_{S} 3.5 \mathrm{~km} \mathrm{~s}^{-1}$, and density $2700 \mathrm{~kg} \mathrm{~m}^{-3}$, roughly consistent with the upper crustal velocity model obtained in Section 2.1). Synthetic waveforms were corrected to $P$ and $S$ arrival times picked from broad-band records, and weighted in the inversion according to azimuthal density. $P, p P$ and $s P$ phases were modelled on 30 s vertical component seismograms, and $S$ and $s S$ phases on $40 \mathrm{~s}$ transverse component seismograms. In this way, we solved for the minimum misfit strike, dip, rake, centroid depth, seismic moment and source-time function of each of the main shocks (Molnar \& Lyon-Caen 1989).

Resulting focal mechanisms are plotted in Figs 2 and 3(b), waveform data and model misfits are shown in Figs 4(a)-(c), and model parameters are tabulated in Table 1 alongside published solutions from the USGS and GCMT catalogues. All three main shocks exhibit predominantly reverse mechanisms with NW-SE trending, moderate $\sim 30^{\circ}-60^{\circ}$-dipping nodal planes. Minimum misfit centroid depths are $\sim 5 \mathrm{~km}$ for E1, $\sim 10 \mathrm{~km}$ for E2 and just $\sim 2 \mathrm{~km}$ for E1. To investigate uncertainties in this key parameter, we performed additional inversions with depths fixed at increments away from the minimum misfit values (e.g. Taymaz et al. 1991; Nissen et al. 2014). Curves of goodness of fit are shown in Fig. 4(d) and are discussed further in light of InSAR modelling results in Section 3. 


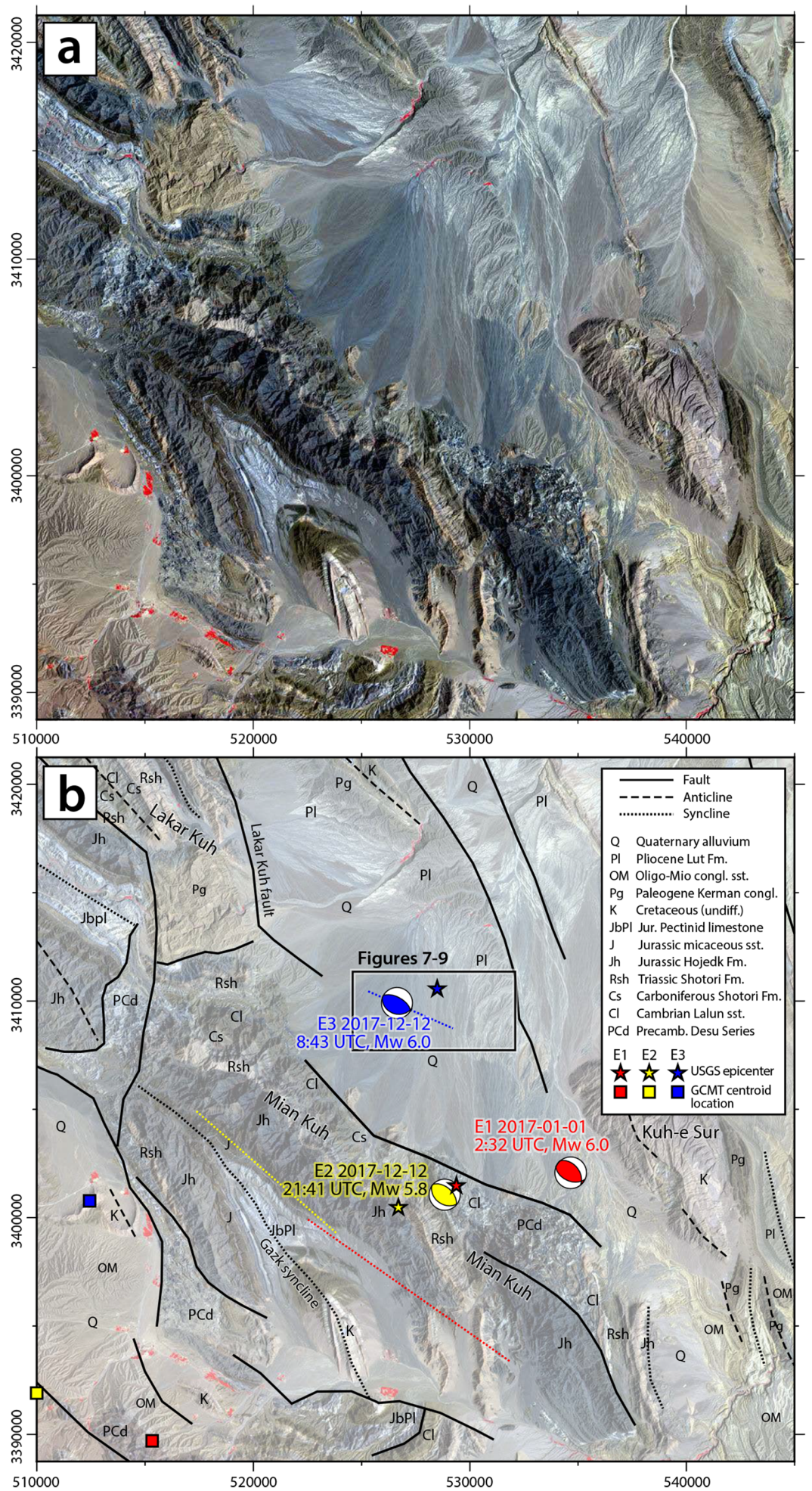

Figure 3. (a) Landsat image of the epicentral region, with coordinates in UTM zone $40 \mathrm{~m}$. (b) Active faults mapped by Walker et al. (2010) and other structural features and lithologies compiled from regional geological maps. Focal mechanisms for E1 (red), E2 (yellow) and E3 (blue) from teleseismic body waveform modelling are plotted at relocated epicentres; catalogue locations are indicated by stars (USGS epicentres) and squares (GCMT centroids). Red, yellow and blue dotted lines show surface projections of the equivalent uniform slip model faults, none of which align closely with previously mapped faults.

\subsection{Aftershock focal mechanisms from first motion polarities}

We estimated focal mechanisms of 45 smaller aftershocks with local magnitudes $\left(M_{\mathrm{N}}\right) \geq 4.6$ using local, regional and teleseismic first $P$ motion polarities processed in SEISAN software (Havskov et al. 2012). Local and regional waveforms were taken from permanent stations of the Institute of Geophysics, University of Tehran (IGUT) network (a mixture of Kinemetrics SS1 Ranger short 
E1: 1 December 2017 02:32

Strike $310^{\circ} \mid$ Dip $49^{\circ} \mid$ Rake $98^{\circ} \mid$ Depth $5 \mathrm{~km} \mid$ Moment $1.44 \times 10^{18} \mathrm{Nm}$

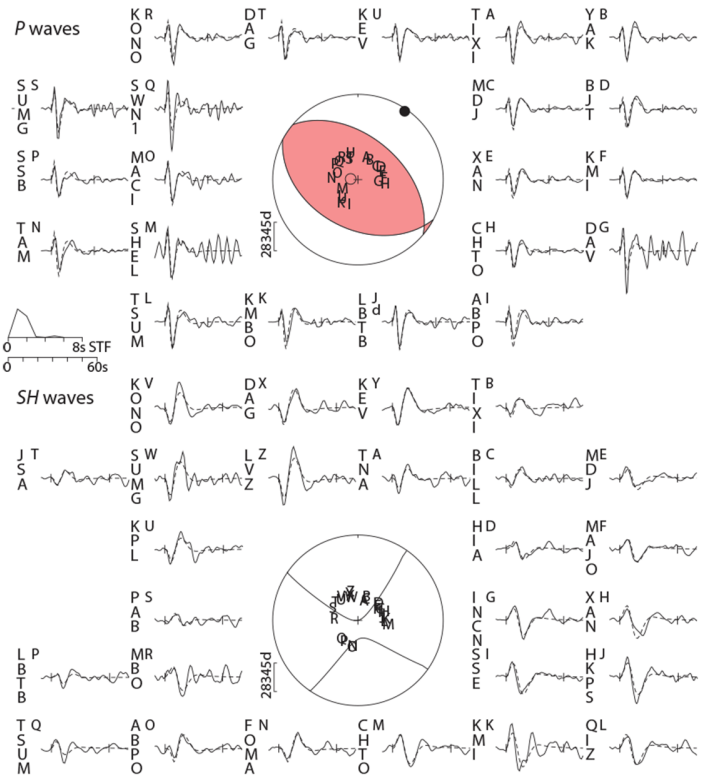

C E3: 12 December 2017 21:41

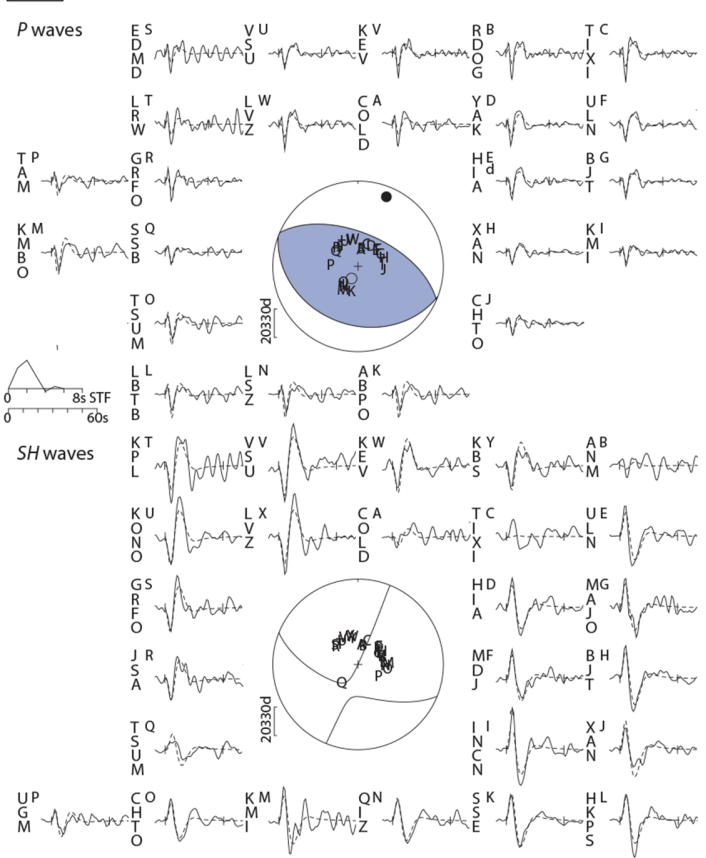

E2: 12 December 2017 08:43

b Strike $311^{\circ} \mid$ Dip $54^{\circ} \mid$ Rake $91^{\circ}$ | Depth $10 \mathrm{~km} \mid$ Moment $0.67 \times 10^{18} \mathrm{Nm}$
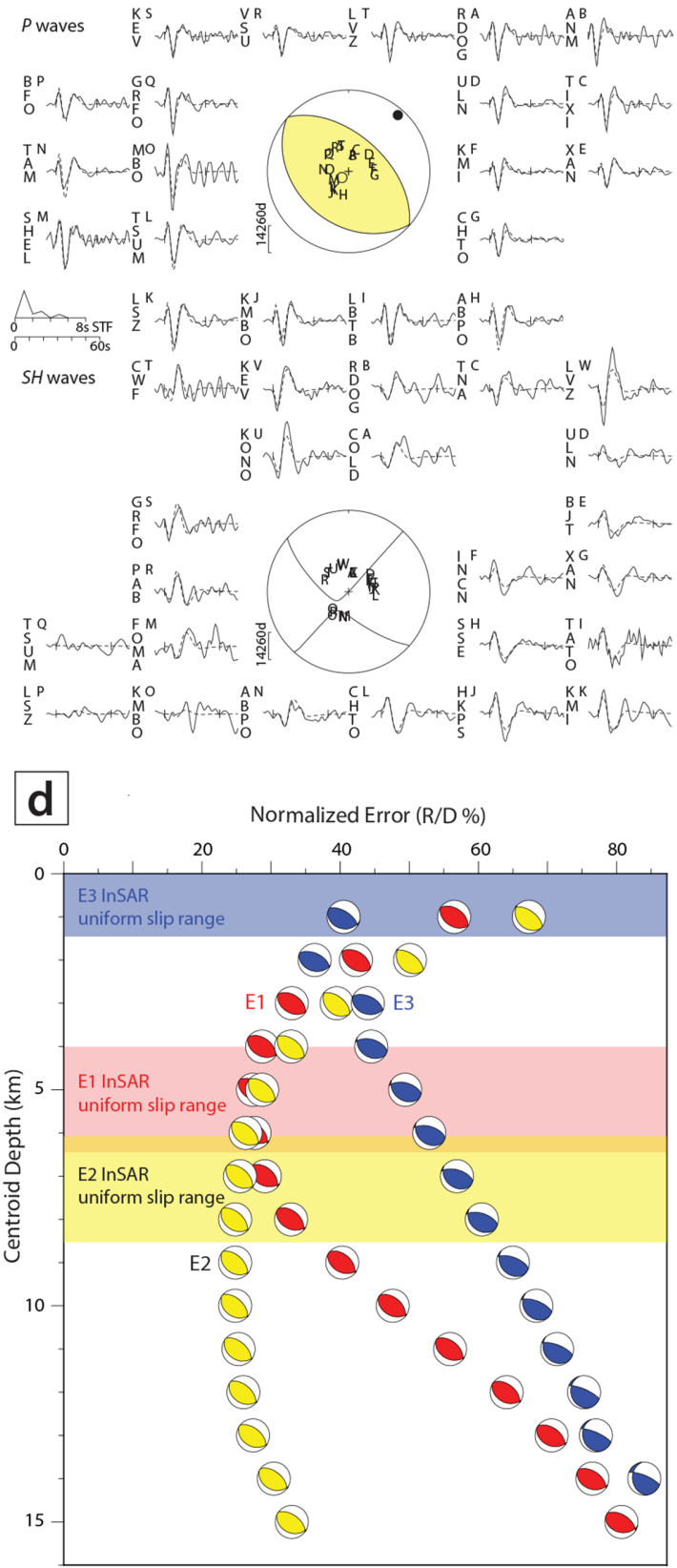

Figure 4. (a) E1 teleseismic body waveform model. The upper part shows the $P$ focal sphere with nodal planes (lines), station positions (capital letters), and $P$ and $T$ axes (solid and open circles), surrounded by observed (solid) and synthetic (dashed) seismograms, with station codes written vertically next to the focal sphere station position letter. Vertical ticks mark the $P$ arrival time and the inversion window end. The lower part shows the $S H$ focal sphere and seismograms. The source-time function and a waveform time scalebar are shown on the left. (b) E2 and (c) E3 body waveform models, with layout as in (a). (d) Focal mechanisms of E1 (red), E2 (yellow) and E3 (blue) and model misfits as a function of fixed centroid depth. Normalized error is a measure of the misfit between observed and synthetic waveforms (Zwick et al. 1994). Shading shows depth ranges of slip in our InSAR uniform slip models, coloured by event.

period and Nanometrics Trillium $40 \mathrm{~s}$ medium period seismometers) and from the IIEES (mostly Guralp CMG-3T broad-band sensors). Since errors in earthquake locations and depths can influence the focal mechanism solution, we used the relocated hypocentres from Section 2.1 for all events. Of the 45 resulting focal mechanisms we consider 16 as robust, each with at least 12 polarity readings and azimuthal gaps $<120^{\circ}$ (Table 2 and Supporting In- formation Fig. S4). Eight of these events occurred before E2 and the other eight after E3. Two additional aftershocks have published focal mechanisms from the GCMT catalogue (one of them also from the USGS) but both have highly non-double couple solutions and we were unable to establish corresponding first motions mechanisms. 
Table 1. Source parameters of the three Hojedk main shocks. Origin times are those yielded by calibrated earthquake relocations. Location refers to the USGS epicentre, the GCMT centroid, the midpoint of the uniform slip plane for our InSAR solutions and the relocated epicentre for our seismological solutions. Depth is the centroid depth for all of the seismological solutions, and the centre depth of the uniform slip plane for the InSAR solution. InSAR moment is calculated from the variable slip models.

\begin{tabular}{|c|c|c|c|c|c|c|c|c|}
\hline Event & Source & Location & Strike & Dip & Rake & Depth & Moment (Nm) & $M_{\mathrm{W}}$ \\
\hline E1 & USGS W-phase & $30.75^{\circ}, 57.31^{\circ}$ & $320^{\circ}$ & $45^{\circ}$ & $109^{\circ}$ & $13.5 \mathrm{~km}$ & $1.51 \times 10^{18}$ & 6.1 \\
\hline 2017-12-01 & USGS body wave & $30.75^{\circ}, 57.31^{\circ}$ & $322^{\circ}$ & $56^{\circ}$ & $104^{\circ}$ & $6 \mathrm{~km}$ & $1.09 \times 10^{18}$ & 6.0 \\
\hline \multirow[t]{2}{*}{$02: 32: 44$} & GCMT & $30.64^{\circ}, 57.16^{\circ}$ & $310^{\circ}$ & $61^{\circ}$ & $95^{\circ}$ & $12 \mathrm{~km}$ & $1.63 \times 10^{18}$ & 6.1 \\
\hline & This study (seismology) & $30.751^{\circ}, 57.362^{\circ}$ & $310^{\circ}$ & $49^{\circ}$ & $98^{\circ}$ & $5 \mathrm{~km}$ & $1.44 \times 10^{18}$ & 6.0 \\
\hline E2 & USGS W-phase & $30.74^{\circ}, 57.28^{\circ}$ & $312^{\circ}$ & $51^{\circ}$ & $94^{\circ}$ & $7.2 \mathrm{~km}$ & $0.84 \times 10^{18}$ & 5.9 \\
\hline $2017-12-12$ & GCMT & $30.66^{\circ}, 57.10^{\circ}$ & $309^{\circ}$ & $64^{\circ}$ & $92^{\circ}$ & $12 \mathrm{~km}$ & $1.27 \times 10^{18}$ & 6.0 \\
\hline E3 & USGS W-phase & $30.83^{\circ}, 57.30^{\circ}$ & $108^{\circ}$ & $31^{\circ}$ & $81^{\circ}$ & $11.5 \mathrm{~km}$ & $1.47 \times 10^{18}$ & 6.0 \\
\hline $2017-12-12$ & USGS body wave & $30.83^{\circ}, 57.30^{\circ}$ & $98^{\circ}$ & $25^{\circ}$ & $68^{\circ}$ & $4 \mathrm{~km}$ & $0.94 \times 10^{18}$ & 5.9 \\
\hline \multirow[t]{3}{*}{$21: 41: 29$} & GCMT & $30.74^{\circ}, 57.13^{\circ}$ & $112^{\circ}$ & $31^{\circ}$ & $94^{\circ}$ & $12 \mathrm{~km}$ & $1.43 \times 10^{18}$ & 6.0 \\
\hline & This study (InSAR) & $30.81^{\circ}, 57.28^{\circ}$ & $114^{\circ a}$ & $30^{\circ}$ & $92^{\circ}$ & $0.75 \mathrm{~km}$ & $1.22 \times 10^{18}$ & 6.0 \\
\hline & This study (seismology) & $30.822^{\circ}, 57.279^{\circ}$ & $110^{\circ}$ & $32^{\circ}$ & $88^{\circ}$ & $2 \mathrm{~km}$ & $1.35 \times 10^{18}$ & 6.0 \\
\hline
\end{tabular}

${ }^{a}$ Parameter fixed in inversion.

Table 2. Source parameters of 18 smaller aftershocks. Location is the relocated epicentre for our own solutions, the USGS epicentre, or the GCMT centroid. Focal mechanisms are first motion mechanisms for our own solutions, and centroid solutions for the USGS (W-phase) and GCMT solutions.

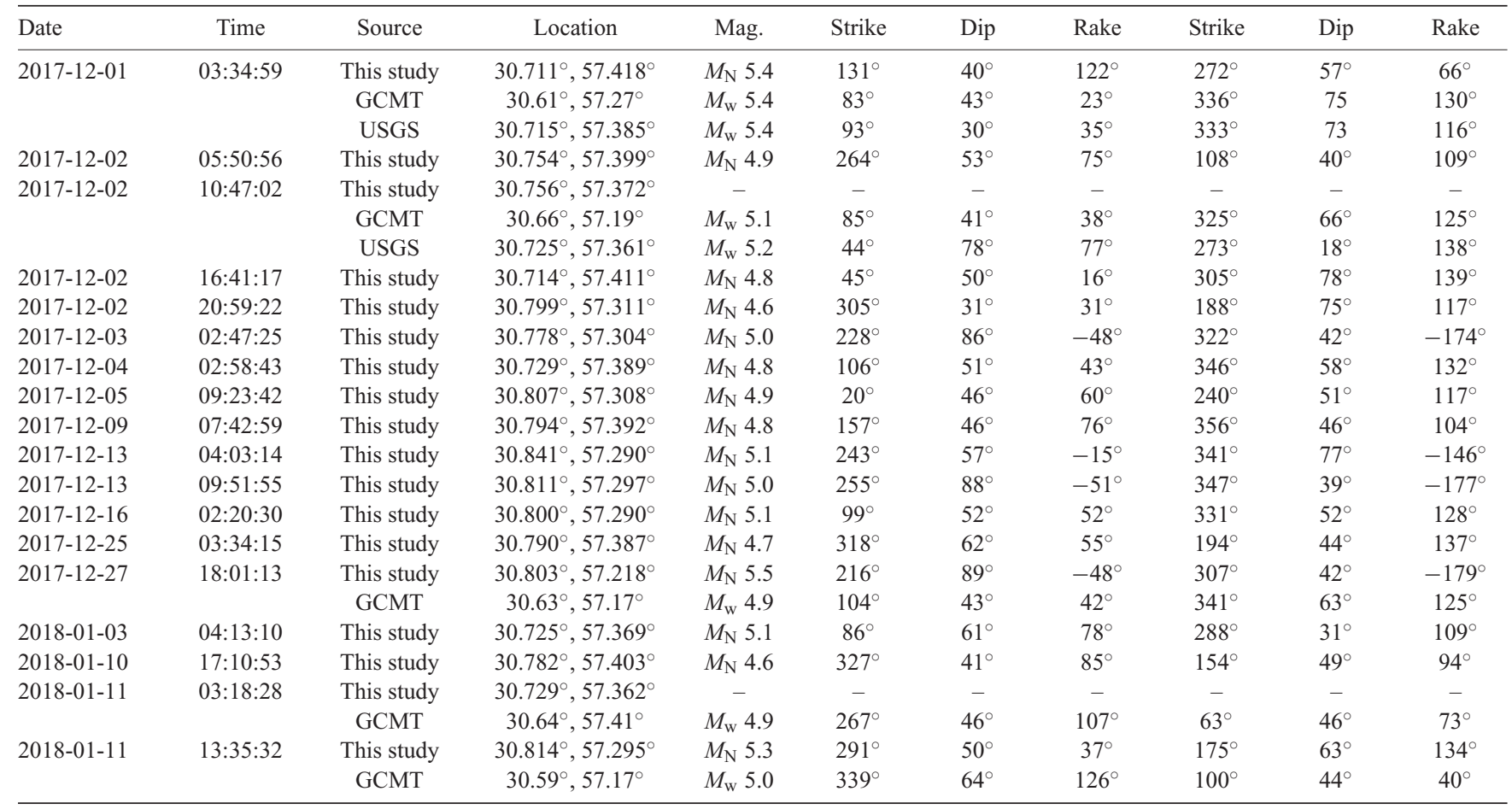

The aftershocks show a much greater diversity of mechanisms than the three main shocks, especially in the cluster of events surrounding E3 (Fig. 2). Many of them exhibit significant strike-slip components, though these events do not line up along a clear trend, making it hard to distinguish the fault and auxiliary nodal planes. Nevertheless, most $\mathrm{P}$ axes lie at N-S or NE-SW azimuths (Supporting Information Fig. S4), roughly consistent with regional tectonics. The pair of aftershocks that also have GCMT/USGS $W$-phase solutions exhibit markedly different first motions and centroid nodal plane orientations, implying significant source complexity. This may reflect the complexity in local faulting and structure that is evident from satellite imagery and geological maps of the area (Fig. 3b).

\section{FAULT GEOMETRIES AND SLIP DISTRIBUTIONS FROM InSAR}

We used Sentinel-1 radar imagery to map coseismic surface deformation in the Hojedk earthquakes, and elastic dislocation modelling to characterize the causative faulting. Using GAMMA software, we constructed coseismic interferograms on ascending tracks 57A and 159A and descending tracks 93D and 166D, giving four independent look angles with incidence angles of between $\sim 33^{\circ}$ and $\sim 46^{\circ}$ in the epicentral area. We made four interferograms capturing only the 2017 December 1 E1 main shock, using pre-earthquake scenes collected on 2017 March 10 (track 159A) and 2017 November 10-30 (other tracks) and post-earthquake scenes collected on 2017 December 4-7. We constructed four more interferograms capturing both 
2017 December 12 E2 and E3 main shocks, using pre-earthquake scenes from 2017 December 4 to 12 coupled with post-earthquake scenes from 2018 March 29 (track 159A) and 2017 December 1631 (other tracks).

To model the causative faulting, we jointly inverted the four interferograms spanning E1 and, separately, the four spanning E2 and E3. Unwrapped line-of-sight surface displacements were first downsampled using a Quadtree algorithm that focuses sampling in areas with steep deformation gradients (Jónsson et al. 2002). We then solved for the strike, dip, rake, uniform slip, fault centre surface projection longitude and latitude, fault length, and top and bottom depths of a rectangular fault plane (E1) or planes (E2 and E3) embedded within an elastic half-space (Okada 1985) with Lamé parameters $\mu=3.2 \times 10^{10} \mathrm{~Pa}$ and Poisson ratio 0.25 , consistent with the velocity structure in Section 2 . Simultaneously, we solved for linear $\mathrm{N}-\mathrm{S}$ and $\mathrm{E}-\mathrm{W}$ orbital ramps and an ambiguity in the zero displacement level for each interferogram. To ensure we achieved the global minimum solution, we used Powell's algorithm with multiple Monte Carlo restarts (Press et al. 1992; Clarke et al. 1997; Wright et al. 1999). Having established a uniform slip model, we then extended and subdivided the model fault plane into $1 \mathrm{~km} \times 1 \mathrm{~km}$ subfaults across which we solved for variable slip, using a Laplacian smoothing operator to limit slip gradients between adjacent patches (Wright et al. 2003).

\subsection{E1 (2017 December 1)}

Interferograms spanning E1 show an elongate, NW-SE-oriented fringe ellipse containing ground motions towards the satellite (Fig. 5, left column of panels). Such a pattern is consistent with a buried reverse fault dipping either NE or SW, an ambiguity similar to that of the fault and auxiliary nodal planes of focal mechanisms (Lohman \& Barnhart 2010; Nissen et al. 2010; Roustaei et al. 2010; Copley et al. 2015). Consequently, we evaluated in turn both possible fault dip directions. Because of the usual trade-off between slip and down-dip fault width, the initial uniform slip planes were established using fixed slip of $1 \mathrm{~m}$. Observed surface displacements are well-reproduced by a $\sim 45^{\circ} \mathrm{NE}$-dipping model reverse fault that projects to the surface along the SW edge of the Mian Kuh range (Fig. 5, middle column), or a $\sim 39^{\circ} \mathrm{SW}$-dipping model reverse fault that projects to the surface in the basin north of the Mian Kuh (Supporting Information Fig. S5, middle column). Slip in both models is centred beneath the northern flank of the Mian Kuh range and concentrated at depths of $\sim 4-6 \mathrm{~km}$, consistent with the $\sim 5 \mathrm{~km}$ centroid depth obtained in Section 2.2. The correct model fault cannot be identified on the basis of root mean square residual displacements, which are slightly smaller for the NW-dipping geometry $(0.73 \mathrm{~cm})$ than for the SW-dipping geometry $(0.78 \mathrm{~cm})$ but which cannot easily be distinguished visually (Fig. 5 and Supporting Information Fig. S5, right columns).

However, our relocated E1 hypocentre lies at the bottom edge of the NE-dipping model slip plane, but at the top edge of the SWdipping model plane (middle columns of Figs 5 and S5). Because the earthquake is more likely to have ruptured upwards from the base of the fault than downwards from the top of it, we consider the first, NE-dipping geometry to be most credible (Fig. 5). Furthermore, the NE-dipping model fault and the corresponding nodal planes of the seismological focal mechanisms (Table 1) consistently include a small right-lateral slip component, consistent with regional tectonics, whereas the SW-dipping model fault and nodal planes include a less plausible left-lateral slip component.
Our preferred InSAR fault model is in close agreement with our body waveform focal mechanism, with differences of only a few degrees in strike, dip and rake (Table 1). The InSAR model seismic moment of $\sim 1.6 \times 10^{18} \mathrm{Nm}\left(M_{\mathrm{w}} 6.1\right)$ is probably within error of that of our seismological solutions, implying a minor contribution to the interferograms from post-seismic deformation. The model slip distribution and relocated epicentre together imply that the earthquake was bilateral, but that it ruptured slightly further along strike towards the NW than towards the SE (Fig. 5, middle column). Overall, the rupture extends much further in the along-strike dimension ( $\sim 16 \mathrm{~km}$ where slip exceeds $0.2 \mathrm{~m})$ than in the downdip dimension ( $\sim 5-6 \mathrm{~km})$, producing an elongate pattern similar to those observed in some reverse faulting earthquakes in the Zagros mountains of southwestern Iran (Roustaei et al. 2010; Copley et al. 2015; Elliott et al. 2015; Nissen et al. 2019). We return to this point in Section 5.

\subsection{E2 and E3 (2017 December 12, 08:43 and 21:41 UTC)}

Interferograms spanning the 2017 December 12 E2 and E3 main shocks display a relatively complex fringe pattern, with several discrete deformation lobes of a variety of orientations and spatial scales (Fig. 6, left column of panels). The InSAR displacements also decorrelate badly within the core of the deformed area close to the relocated E3 epicentre, likely due to very steep local phase gradients, surface faulting or fracturing, or strong ground accelerations that may have moved individual scatterers (e.g. Simons et al. 2002). Inverting downsampled surface displacements for slip on two model faults results in a very large number of free parameters, and we were unable to obtain a satisfactory, stable solution without first fixing certain parameters. For the southern model fault, representing E2, we fixed the strike, dip and rake to those of our body waveform model, testing both NE- and SW-dipping nodal planes in turn. For the northern model fault, representing E3, we fixed the fault centre surface projection, strike and zero top depth, but allowed all other parameters to vary. The fixed strike of $114^{\circ}$ was chosen to match a band of decorrelation in the interferograms, but is also close to the $110^{\circ}$ value obtained by body waveform modelling.

We were able to reproduce the observed pattern of fringes reasonably well with these two model faults, incorporating either a NE or SW dip direction for the one representing E2 (middle columns of Fig. 6 and Supporting Information Fig. S6). Seismic moments are $\sim 0.6 \times 10^{18} \mathrm{Nm}\left(M_{\mathrm{w}} 5.8\right)$ for E2, regardless of its dip direction, and $\sim 1.2 \times 10^{18} \mathrm{Nm}\left(M_{\mathrm{w}} 6.0\right)$ for E3; both values are similar to our seismological solutions implying little contribution to the geodetic model from postseismic deformation (Table 1). Root mean square residuals are $1.76 \mathrm{~cm}$ when $\mathrm{E} 2$ dips towards the NE, and $1.51 \mathrm{~cm}$ when E2 dips towards the SW (Figs 6 and S6, right columns). However, we prefer the NE-dipping E2 geometry, since its relocated hypocentre aligns with the base of this model fault from which rupture would have propagated upwards (Fig. 6). The alternative SW-dipping E2 model fault would in contrast imply rupture nucleation at the top of the fault plane, which seems to us less likely (Supporting Information Fig. S6).

The preferred NE-dipping E2 model fault dips $54^{\circ} \mathrm{NE}$ and (like E1) reverse slip is focused along an elongate, narrow plane $(\sim 13 \mathrm{~km}$ $\times 3 \mathrm{~km}$ where slip is $>0.2 \mathrm{~m}$ ) beneath the northern slope of the Mian Kuh mountains (Fig. 6, middle column). Slip is concentrated at depths of $\sim 6-8.5 \mathrm{~km}$, shallower than the minimum misfit centroid depth of $\sim 10 \mathrm{~km}$ from body waveform modelling. However, in 

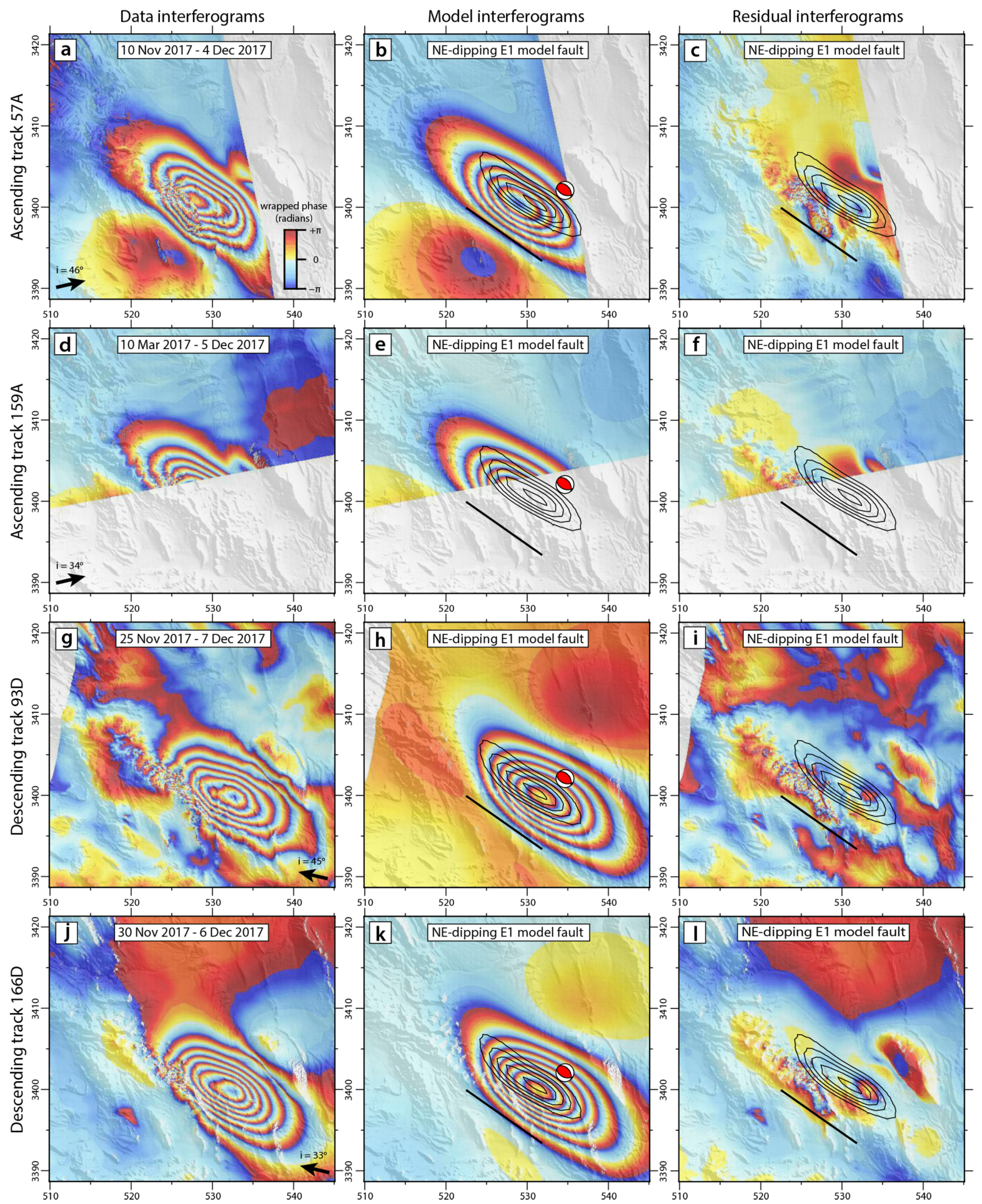

Figure 5. (a) Data, (b) model and (c) residual wrapped interferograms of ascending track 57A spanning the first main shock, E1, showing our preferred, NE-dipping fault model. Coordinates are UTM zone $40 \mathrm{~km}, i$ is the radar incidence angle measured from the vertical in the epicentral region, and $2 \pi$ radians in wrapped phase is equal to $5.55 \mathrm{~cm}$ in line-of-sight displacement. In (b) and (c), the thick black line is the surface projection of the initial uniform slip model fault, and thin lines show $0.2 \mathrm{~m}$ slip contours of the variable slip model. The focal mechanism is our seismological body-waveform model, plotted at its relocated epicentre. (d) Data, (e) model and (f) residual interferograms for ascending track 159A, (g-i) for descending track $93 \mathrm{D}$ and (j-1) for descending track $166 \mathrm{D}$.

Section 2.2 we found that among the three main shocks E2 has the least well-constrained centroid depth, with very little change in data-model misfit across the full InSAR slip range (Fig. 4d). E2's relocated hypocentre lies close to the SE end of its InSAR slip patch, implying unilateral rupture towards the northwest (Fig. 6). The E2 model fault is closely aligned with the northwestern part of the E1 model fault (shown most clearly in Fig. 3b), a point discussed further in Section 5. 

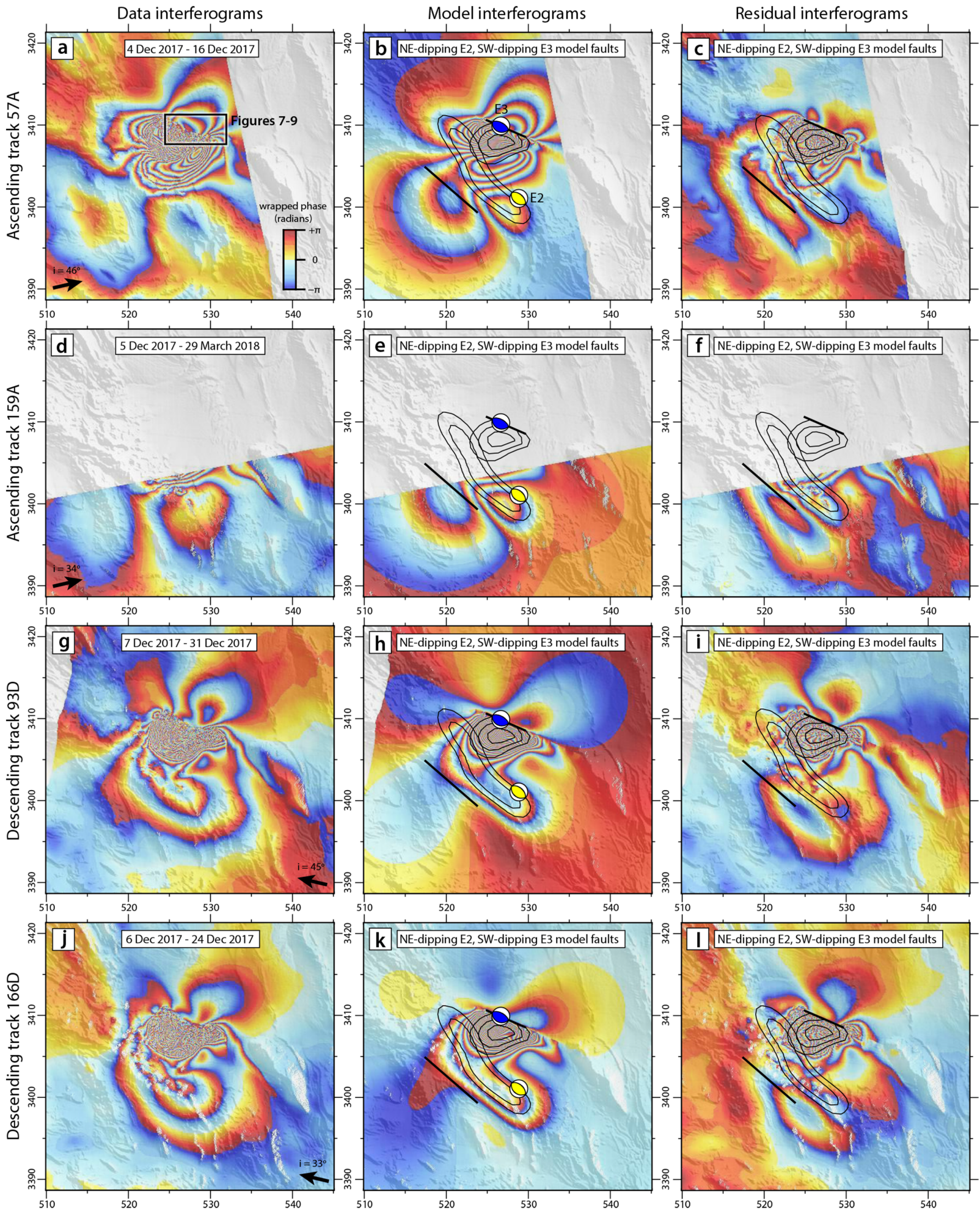

Figure 6. Data, model and residual interferograms for the second (E2) and third (E3) main shocks, showing our preferred model with an NE-dipping E2 fault. The layout and annotations are the same as for Fig. 5, except that the southern E2 and northern E3 slip contours are plotted at 0.1 and $0.5 \mathrm{~m}$ increments, respectively. The E2 body waveform focal mechanism is in yellow and the E3 mechanism is in blue, both plotted at their relocated epicentres.

The E3 model fault dips $\sim 30^{\circ} \mathrm{SW}$ and involves pure reverse slip concentrated at very shallow depths of $\sim 0-3 \mathrm{~km}$ on a short and narrow fault plane $(\sim 7 \mathrm{~km} \times 6 \mathrm{~km}$ where slip exceeds $0.5 \mathrm{~m})$ that surfaces $\sim 5 \mathrm{~km}$ north of the Mian Kuh (Fig. 6, middle column).
However, relatively large residual displacements in this area suggest that the model fault geometry is imperfect (Fig. 6, right column). In Section 4, we shall see that the E3 surface rupture is highly sinuous and may be accompanied by a shorter, conjugate fault or faults. 

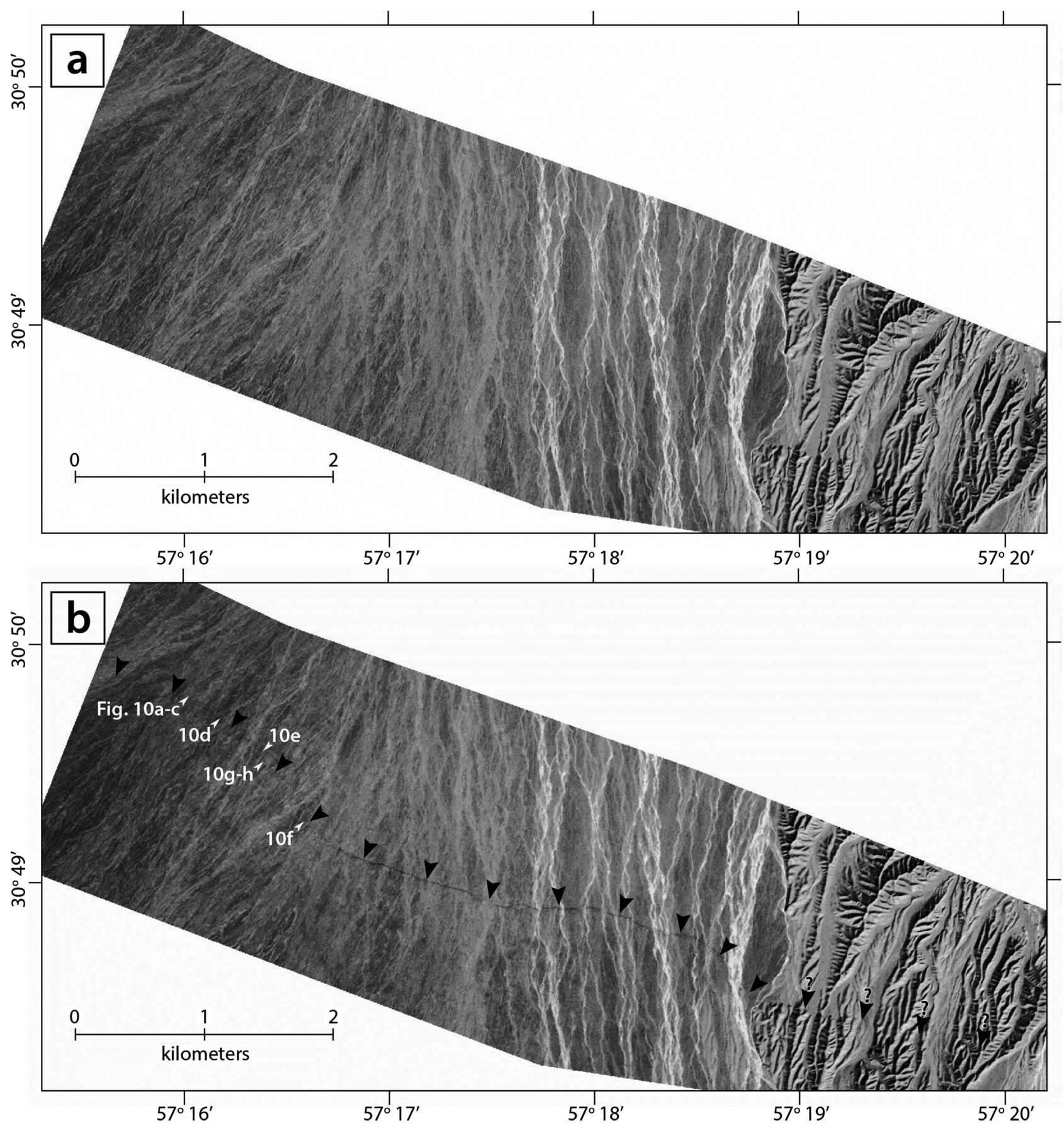

Figure 7. (a) Planet Labs satellite image acquired on 2017 December 12 at $\sim 10: 15$ a.m. local time, showing alluvial fans in the basin north of the Mian Kuh range (see Fig. 3b for location). (b) Planet Labs satellite image acquired on 2017 December 14 at $~ 10: 15$ a.m. local time, with the fresh E3 surface rupture picked out by black arrows. Smaller white arrows mark locations of field photographs in Fig. 10. The approximate illumination direction in both images is from the SE.

This implies that E3 is poorly represented by a single plane, helping explain the relatively large residual displacements in our simple dislocation model. Nevertheless, the close match between our body waveform and InSAR fault parameters (Table 1) suggests that we have captured the overall geometry and kinematics reasonably well. Our relocated E3 epicentre aligns centrally along the top edge of the model fault plane, but given epicentral uncertainties exceeding $\sim 1 \mathrm{~km}$ and the highly concentrated slip distribution we do not attach significance to this result.

\section{E 3 (2017 DECEMBER 12 21:41 UTC) SURFACE RUPTURES}

\subsection{Optical satellite image correlation}

We correlated Planet Labs satellite images acquired before and after the third main shock (E3) in order to retrieve the near-field horizontal surface displacement pattern where our InSAR modelling suggests the E3 fault ruptured the surface. Pre-earthquake imagery was acquired on the 2017 December 10th and 12th (e.g. Fig. 7a) 

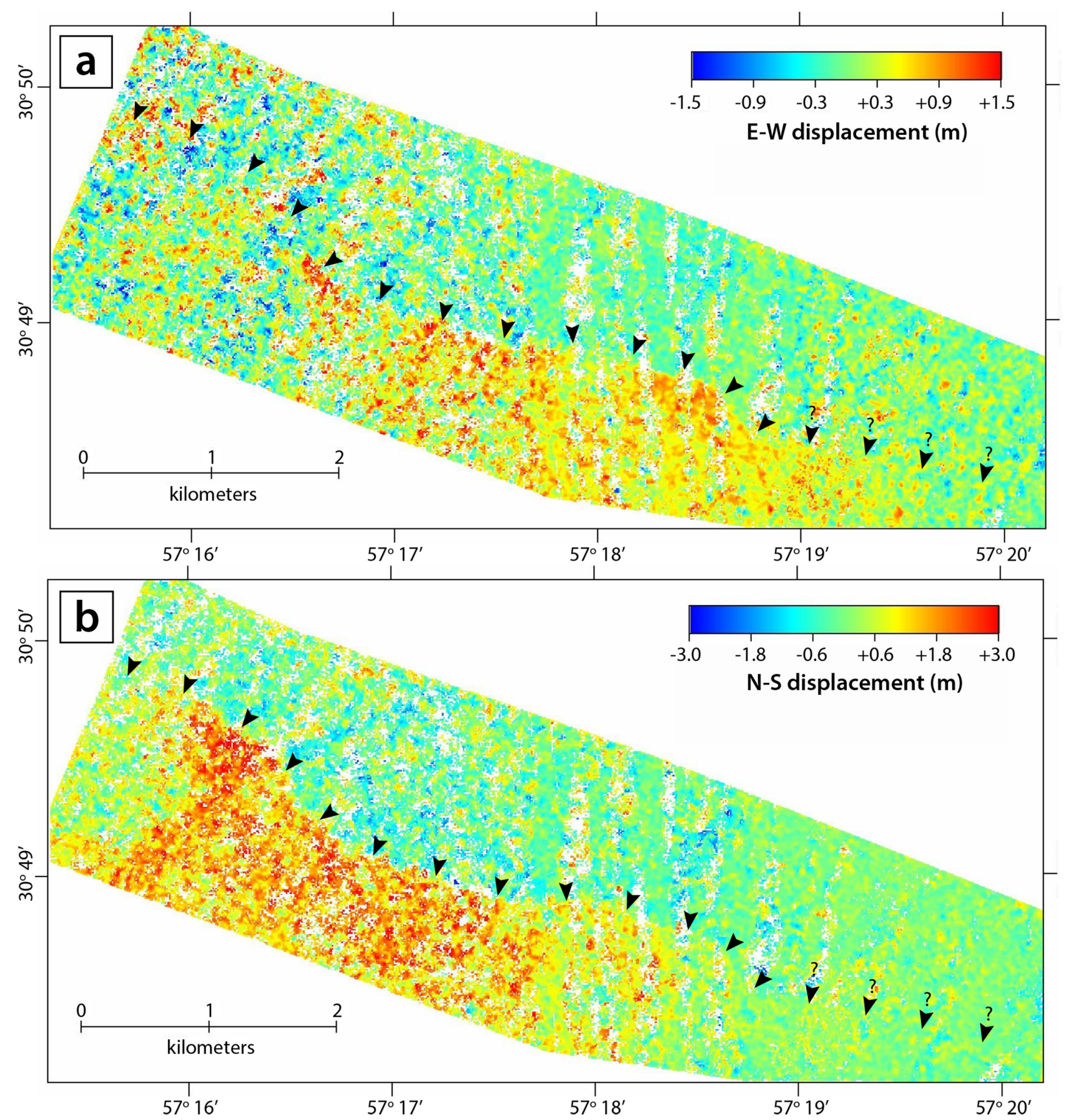

Figure 8. Horizontal surface displacements from sub-pixel correlation of Planet Labs images spanning the E3 earthquake (including those shown in Fig. 7). The E3 surface rupture is picked out by black arrows. (a) East-west displacements, with positive motion towards the east. (b) North-south displacements, with positive motion towards the north.

and post-earthquake imagery on the 2017 December 14th and 17th (Fig. $7 b$ ) at $\sim 10: 15$ a.m. local time in each case, with illumination from the SE. Planet Labs imagery is delivered as an orthorectified product, corrected for topographic distortion and sampled onto a common grid, with pixel resolution $3 \mathrm{~m}$. The post-event imagery shows a sinuous, north-facing scarp crossing the flat alluvial plain north of Mian Kuh over a distance of $\sim 6 \mathrm{~km}$, that is not present in the pre-event imagery. A visual comparison of pre- and postevent images also reveals subtle, banded textural changes in the fault hangingwall, clearest about half a kilometre south of the main scarp both at $\sim 57^{\circ} 16^{\prime} \mathrm{E}$ and $\sim 57^{\circ} 18^{\prime} \mathrm{E}$. These features are unlikely to represent primary surface rupturing (see below) but may indicate secondary fracturing or liquefaction.

We used the optical image correlation software COSI-Corr (Leprince et al. 2007) to retrieve sub-pixel horizontal displacements from the image pairs. Using COSI-Corr's frequency-based correlation scheme, we processed each of the four available coseismic image pairs (10-14 December, 10-17 December, 12-14 December and 12-17 December) and stacked the resulting displacements to help reduce noise. In various tests, we found that band 2 yielded 


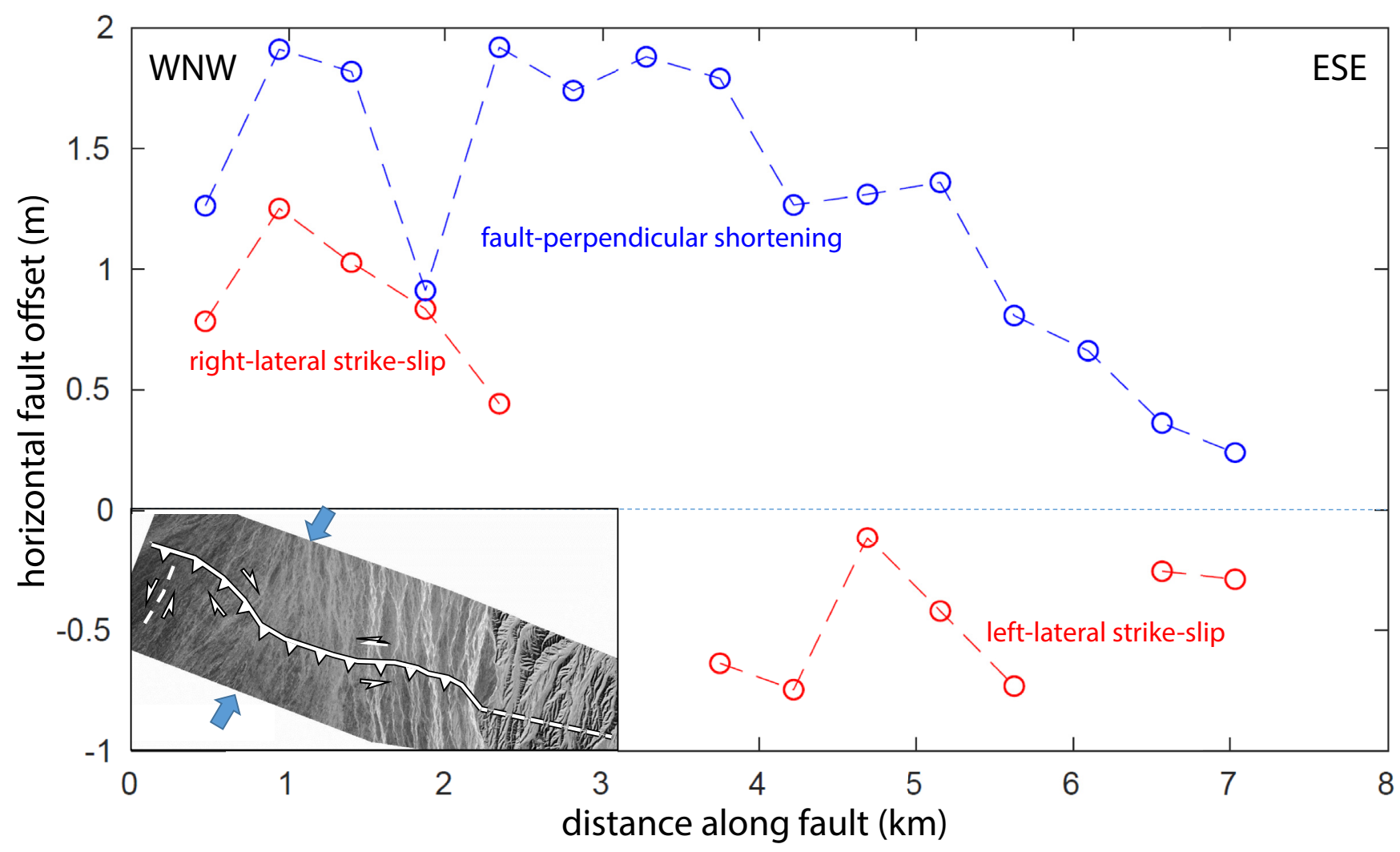

Figure 9. Along-strike variations in horizontal surface slip in the E3 earthquake, as determined by profiling the horizontal displacement fields shown in Fig. 8. Circles show discrete measurements, linked by dashed lines, with fault-parallel lateral offsets in red and fault-perpendicular shortening offsets in blue. The inset (lower left) shows a simple interpretation of these offsets.

the cleanest correlation values with lowest noise levels. To maximize coherence, we used a multi-scale sliding correlation window [64/32; see Ayoub et al. (2015)], stepping every 4 pixels (12 m). To reduce the impact from high frequency noise in the images, which tends to corrupt the correlation process, we made use of the iterative frequency masking approach available in COSI-Corr (we used four iterations). The $\mathrm{E}-\mathrm{W}$ and $\mathrm{N}-\mathrm{S}$ displacements were computed from the mean of all four image pair combinations, and then denoised by (1) removing a linear ramp, (2) discarding unrealistic values, (3) detecting and removing outliers based on a local neighbourhood strategy (Kuo et al. 2018; Zinke et al. 2019) and (4) median filtering (3-by-3 kernel). The average noise (standard deviation of displacements) in stable parts of both $\mathrm{E}-\mathrm{W}$ and $\mathrm{N}-\mathrm{S}$ displacement fields is $\sim 30 \mathrm{~cm}$, about one-tenth of the input pixel resolution.

Resulting $\mathrm{E}-\mathrm{W}$ and $\mathrm{N}-\mathrm{S}$ displacement fields are shown in Figs 8(a) and (b), respectively. Sharp displacement discontinuities can be observed in both components, following closely the sinuous trend of the scarp mapped statically in post-earthquake imagery (Fig. $7 b$ ) but possibly extending for an additional $\sim 1-2 \mathrm{~km}$ at its eastern end (between about $\sim 57^{\circ} 19^{\prime}$ and $\sim 57^{\circ} 19^{\prime} \mathrm{E}$ ). The sense of relative displacement across the main rupture is in broad agreement with our E3 InSAR model, with positive N-S displacements in the hangingwall indicating its northward motion relative to the footwall. To investigate these kinematics in more detail, we used swath profiles through the horizontal displacement field to estimate faultperpendicular (shortening) and fault-parallel (strike-slip) offsets at regular $\sim 500 \mathrm{~m}$ intervals along the surface rupture (Milliner et al. 2015). This yielded a clear horizontal shortening signal with peak offsets of up to $\sim 2 \mathrm{~m}$ along the western half of the rupture and average offsets of $\sim 1.3 \mathrm{~m}$ for the whole (Fig. 9). The lateral offsets are more subtle, but seem to indicate up to $\sim 1 \mathrm{~m}$ of right-lateral slip in the west and up to $\sim 0.5 \mathrm{~m}$ of left-lateral slip in the east. The switch in polarity seems to mimic the sinuosity of the surface rupture, with right-lateral offset where it trends $\sim \mathrm{NW}-\mathrm{SE}$ and left-lateral offset where it trends $\sim \mathrm{E}-\mathrm{W}$. This is consistent with mostly reverse slip on a fault with an overall strike of $\sim$ ESE, as depicted in the inset to Fig. 9.

A separate discontinuity can be observed in the $\mathrm{N}-\mathrm{S}$ displacement field to the south of the western main rupture, at around $56^{\circ} 16^{\prime} \mathrm{E}$ (Fig. 8b). This discontinuity is less sharp than that of the main rupture, but trends N-S to NE-SW for at least $\sim 1.5 \mathrm{~km}$ and may even cross over the southern edge of the imagery analysed. The relative sense of displacement across this feature suggests left-lateral slip, and we interpret this feature as a tear fault that accommodates the northward motion of the main hangingwall block (Fig. 9, inset).

\subsection{Field observations}

Due to its remote location a long distance from any road on a coarse, boulder-rich alluvial surface, and limited time, we were only able to visit briefly a $\sim 2 \mathrm{~km}$ section of the E3 surface rupture close to its western end (Fig. 7b). We observed a clear north-facing scarp in coarse alluvial sediments, collapsed to the angle of repose as expected for a rather gently dipping thrust fault (Figs 10a-f). In some places the scarp was expressed as up to three separate strands, but generally we observed only a single trace. Scarp heights were mostly $\sim 50-100 \mathrm{~cm}$ and exceeded $100 \mathrm{~cm}$ in one place. These 

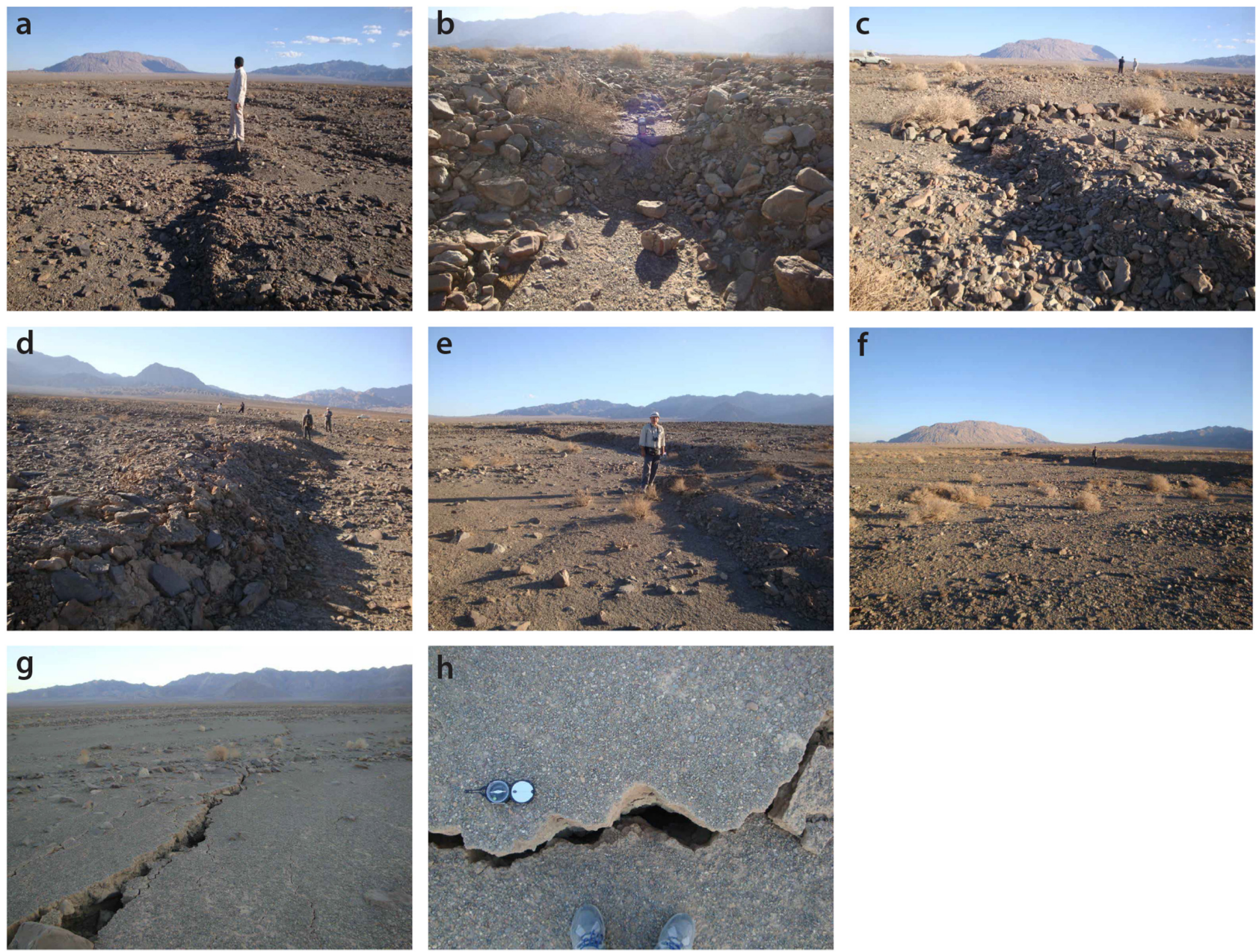

Figure 10. Field photographs of the E3 surface rupture, collected on the afternoon of 2017 December 24. (a) Photograph from $57.26701^{\circ} \mathrm{E}, 30.82965^{\circ} \mathrm{N}$, facing $\sim$ ESE, showing a cumulative $\sim 40-60 \mathrm{~cm}$ vertical offset across at least three strands of scarp. The rounded mountain in the background is Kuh-e Sur (Figs 2 and 3). (b) $57.26682^{\circ} \mathrm{E}, 30.82962^{\circ} \mathrm{N}$, facing $\sim \mathrm{SSW}$, showing $\sim 50 \mathrm{~cm}$ vertical offset with handheld GPS unit for scale. The rugged Mian Kuh mountains are in the distance. (c) $57.26682^{\circ} \mathrm{E}, 30.82963^{\circ} \mathrm{N}$, facing $\sim \mathrm{ESE}$, showing $\sim 50 \mathrm{~cm}$ vertical offset. (d) $57.26951^{\circ} \mathrm{E}, 30.82816^{\circ} \mathrm{N}$, facing $\sim$ WNW, showing $\sim 100 \mathrm{~cm}$ vertical offset. (e) $57.27307^{\circ} \mathrm{E}, 30.82582^{\circ} \mathrm{N}$, facing $\sim \mathrm{SE}$, showing $\sim 80 \mathrm{~cm}$ vertical offset. (f) $57.27642^{\circ} \mathrm{E}, 30.82076^{\circ} \mathrm{N}$, facing $\sim$ ESE, showing $>100 \mathrm{~cm}$ vertical offset. (g) $57.27303^{\circ} \mathrm{E}, 30.82504^{\circ} \mathrm{N}$, facing $\sim \mathrm{SSE}$, showing $\mathrm{N}-\mathrm{S}$-trending fissures. (h) $57.27303^{\circ} \mathrm{E}, 30.82504^{\circ} \mathrm{N}$, with the top edge of the photograph facing $\sim \mathrm{W}$, showing right-lateral fissure offsets.
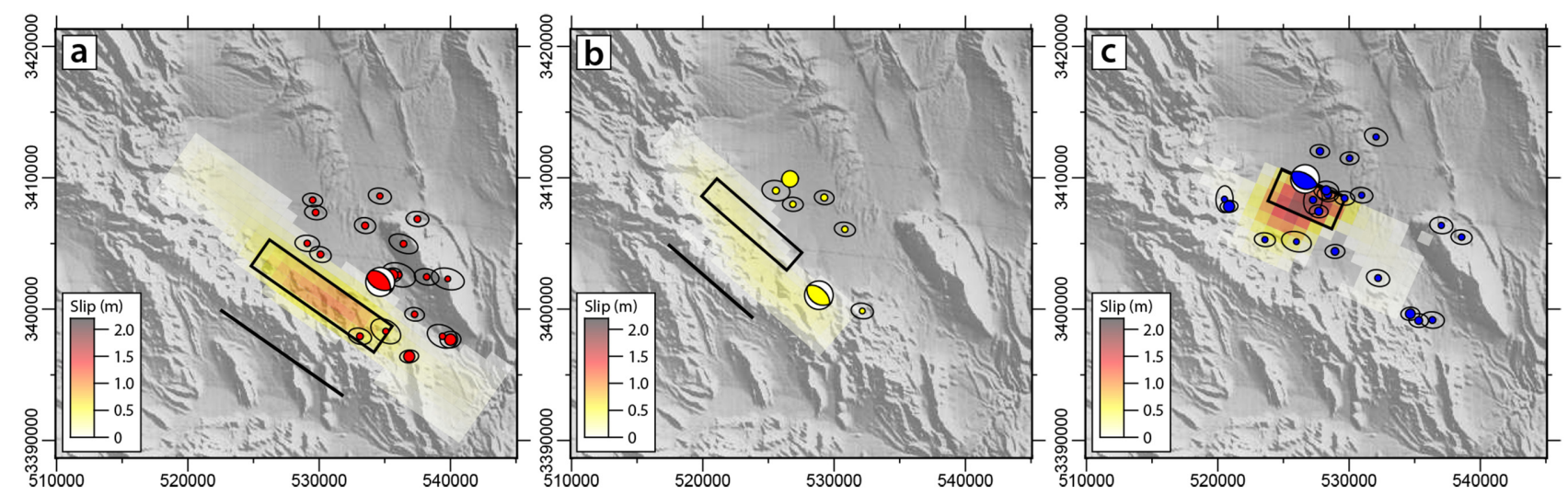

Figure 11. (a) E1 body waveform model and relocated epicentre (red focal mechanism), InSAR-derived uniform slip model fault (extents and up-dip surface projection in black), InSAR-derived variable slip model (colour map), and relocated early aftershocks between 2017 December 1 and 9 (red circles with 90 per cent confidence ellipses). (b) The same, but for E2. The aftershocks are those occurring after E2 and before E3. (c) The same, but for E3. Aftershocks are those occurring after E3. 
values are consistent with earlier geodetic inferences of up to $\sim 2 \mathrm{~m}$ of horizontal shortening (Section 4.1) and an underlying fault dip of $\sim 30^{\circ}$ (Sections 2.2 and 3.2). Projected onto the fault plane, the peaks in throw $(\sim 1 \mathrm{~m})$, heave $(\sim 2 \mathrm{~m})$ and dextral slip $(\sim 1 \mathrm{~m})$ imply maximum net surface slip of $\sim 2.5 \mathrm{~m}$. We did not see clear evidence for lateral offsets across the main scarp, but in the middle part of the section we visited we did observe a set of N-S-trending fissures that accommodated small right-lateral offsets (Figs $10 \mathrm{~g}-\mathrm{h}$ ). This is close to where we estimated peak right-lateral offsets from satellite pixel tracking (Section 4.1). The field observations suggest that this dextral strike-slip component may not be accommodated entirely on the main thrust scarp, but across a broader zone of fracturing and fissuring.

\section{DISCUSSION}

E1 and E2 ruptured NE-dipping reverse slip planes beneath the northern flank of the Mian Kuh range, which is the northeastern limb the large Gazk syncline whose axis plunges southeastwards (Fig. 3b). The two slip planes align very closely considering the assumptions inherent to our InSAR dislocation modelling (e.g. planar faults, uniform elastic properties), suggesting that E1 and E2 ruptured the same fault (Figs 11a-b). Interestingly, E2's epicentre lies within the E1 slip patch, hinting that part of this fault ruptured and reruptured in a pair of earthquakes $12 \mathrm{~d}$ apart. Both produced highly elongate slip distributions that are much narrower down-dip than along-strike. This may imply a structural constraint on the upper and lower edges of slip, perhaps from weak layers within sedimentary rocks of the Mian Kuh. This would mimic patterns inferred for reverse faulting earthquakes buried within the thick sedimentary cover of the Zagros fold-and-thrust belt, such as at Fin in 2006 (Roustaei et al. 2010), Khaki-Shonbe in 2013 (Elliott et al. 2015), Murmuri in 2014 (Copley et al. 2015) and Mandali in 2018 (Nissen et al. 2019). An alternative structural barrier to up-dip rupture propagation in E1 and E2 might be an intersection with conjugate faults (e.g. Elliott et al. 2011), one obvious candidate being the SW-dipping reverse fault bounding the northern margin of the Mian Kuh range (Fig. 3b). Unfortunately, we lack the detailed structural and stratigraphic data that would be needed to probe these possibilities further. Likewise, it is difficult to ascertain whether long-term slip on the E1-E2 reverse fault governs folding of the Gazk syncline, similar to relations inferred in parts of the Zagros (Barnhart \& Lohman 2013; Copley et al. 2015). The E1-E2 fault is likely a southern terminal structure to the right-lateral Lakar Kuh fault, which seems to taper off in this area (Fig. 3b).

E3 ruptured an even shallower thrust fault conjugate to and in the hangingwall of the E1-E2 fault. It nucleated close to where several aftershocks of E1 and E2 had occurred days to hours previously (Figs 2 and 11). With its slip focused on a short $(\sim 7 \mathrm{~km})$, narrow $(\sim 6 \mathrm{~km})$ fault plane at depths of $\sim 0-3 \mathrm{~km}$ (Fig. 11c), E3 likely generated an unusually high stress drop (Wells \& Coppersmith 1994). Its centroid depth of $\sim 2 \mathrm{~km}$ from teleseismic body waveform modelling is the joint shallowest out of more than 200 earthquakes studied using the same or similar procedures over the past few decades, matching only a pair of events in southern and eastern Iran (Byrne et al. 1992; Berberian et al. 1999). Its 6-7 kmlong surface rupture accommodates mean shortening of $\sim 1.3 \mathrm{~m}$, which projected onto the $\sim 30^{\circ}$-dipping fault plane implies average net surface slip of $\sim 1.5 \mathrm{~m}$, also very large for a $M_{\mathrm{w}} 6.0$ earthquake. The rupture crosses a wide, flat alluvial plain north of Mian Kuh, and there is no clear indication of faulting along this trend in pre-earthquake imagery (Fig. 7a). However, the two ends of the surface rupture align with sharp discontinuities in fan morphology, with older, incised fans present only within the hangingwall of the extrapolated fault. Immediately west of E3, this discontinuity is notable even in coarse-resolution Landsat imagery (Fig. 3b); this fault was mapped by Walker et al. (2010) as a short ( $<5 \mathrm{~km})$ thrust splaying off the right-lateral Lakar Kuh fault. The eastern discontinuity is more subtle, and can only be made out on higher-resolution satellite images (Fig. 7). This fault is presumably young, since it has not yet uplifted basement rocks to the point of exposure from beneath the surrounding alluvium, and it may represent basinward migration of thrusting associated with the northern Mian Kuh range.

These observations have broader implications for the growth of topography and seismic hazard in other mountainous parts of Iran. Many alluvial fans flanking actively uplifting mountain ranges show clear indications of fold growth, usually acknowledged as the surface expression of blind or partially blind reverse faults (e.g. Walker et al. 2003; Talebian et al. 2016). However, the 2017 Hojedk earthquakes indicate that some thrust faults in similar settings may be capable of very shallow rupture, even producing multimetre surface slip. Furthermore, such faults may not have a clear geomorphic expression, thus hindering their identification.

\section{CONCLUSIONS}

The December 2017 Hojedk earthquake triplet occurred in a major restraining bend north of Kerman, Iran. The first and second main shocks on 1 December $\left(M_{\mathrm{w}} 6.0-6.1\right)$ and 12 December $\left(M_{\mathrm{w}}\right.$ 5.8) ruptured and reruptured a blind, NE-dipping reverse fault beneath the Mian Kuh mountain range. Both produced elongate slip patches that may reflect structural limits on up- and down-dip rupture propagation. The third main shock later on 12 December $\left(M_{\mathrm{w}}\right.$ 6.0) occurred on a conjugate SW-dipping reverse fault in the hangingwall of the earlier ruptures. Slip was concentrated at unusually shallow depths of $\sim 0-3 \mathrm{~km}$, generating a $\sim 7 \mathrm{~km}$-long, sinuous surface rupture crossing the broad alluvial plane north of the Mian Kuh. Neither fault had been recognized prior to the 2017 earthquakes. The possibility of such shallow rupture on faults with faint geomorphic expressions is of wider concern to Iran and other collisional settings.

\section{ACKNOWLEDGEMENTS}

ES was supported by an Undergraduate Summer Research Award (USRA) from the Natural Sciences and Engineering Research Council of Canada (NSERC). EN also acknowledges funding from NSERC through Discovery Grant 2017-04029, the Canada Foundation for Innovation (CFI), the British Columbia Knowledge Development Fund (BCKDF), the Canada Research Chair program, and the U. S. National Science Foundation (NSF) through grant EAR 1524815. Phase arrival time data were gathered from the Building and House Research Center of Iran (BHRC), the Iranian Seismological Center (IRSC), the Institute of Geophysics, University of Tehran (IGUT), the International Institute of Earthquake Engineering and Seismology (IIEES), the International Seismological Centre (ISC), and the USGS National Earthquake Information Center (NEIC). Teleseismic seismograms were downloaded from the Incorporated Research Institutions for Seismology Data Management Center (IRIS DMC). SAR interferograms were made using European Space Agency Copernicus Sentinel data [2017]; initial InSAR data reconnaiscance was aided through use of the University 
of Alaska Fairbanks SARVIEWS web portal (Meyer et al. 2017), which is funded by the National Aeronautics and Space Administration (NASA). Optical satellite images were provided by Planet Labs, Inc. Most of the figures were plotted using the NSF-supported Generic Mapping Tools (Wessel et al. 2013). Finally, we are grateful to James Jackson for reviewing an earlier version of the paper.

\section{REFERENCES}

Ayoub, F., Leprince, S. \& Avouac, J.-P., 2015. User's Guide to COSI-CORR Co-registration of Optically Sensed Images and Correlation, California Institute of Technology.

Baker, C., 1993. The active seismicity and tectonics of Iran, PhD thesis, University of Cambridge.

Barnhart, W.D. \& Lohman, R.B., 2013. Phantom earthquakes and triggered aseismic creep: vertical partitioning of strain during earthquake sequences in Iran, Geophys. Res. Lett., 40(5), 819-823.

Berberian, M. \& Yeats, R.S., 1999. Patterns of historical earthquake rupture in the Iranian Plateau, Bull. seism. Soc. Am., 89(1), 120-139.

Berberian, M., Jackson, J.A., Qorashi, M., Khatib, M.M., Priestley, K., Talebian, M. \& Ghafuri-Ashtiani, M., 1999. The 1997 May 10 Zirkuh (Qa'enat) earthquake ( $M_{w}$ 7.2): faulting along the Sistan suture zone of eastern Iran, Geophys. J. Int., 136, 671-694.

Berberian, M. et al., 2001. The 1998 March 14 Fandoqa earthquake $\left(M_{w}\right.$ 6.6) in Kerman province, southeast Iran: re-rupture of the 1981 Sirch earthquake fault, triggering of slip on adjacent thrusts and the active tectonics of the Gowk fault zone, Geophys. J. Int., 146, 371-398.

Bergman, E.A. \& Solomon, S.C., 1990. Earthquake swarms on the MidAtlantic Ridge - products of magmatism or extensional tectonics?, J. geophys. Res., 95, 4943-4965.

Byrne, D.E., Sykes, L.R. \& Davis, D.M., 1992. Great thrust earthquakes and aseismic slip along the plate boundary of the Makran Subduction Zone, J. geophys. Res., 97, 449-478.

Clarke, P.J., Paradissis, D., Briole, P., England, P.C., Parsons, B.E., Billiris, H., Veis, G. \& Ruegg, J.-C., 1997. Geodetic investigation of the 13 May 1995 Kozani-Grevena (Greece) earthquake, Geophys. Res. Lett., 24, 707710.

Copley, A., Karasozen, E., Oveisi, B., Elliott, J.R., Samsonov, S. \& Nissen, E., 2015. Seismogenic faulting of the sedimentary sequence and laterally variable material properties in the Zagros Mountains (Iran) revealed by the August 2014 Murmuri (E. Dehloran) earthquake sequence, Geophys. J. Int., 203, 1436-1459.

Elliott, J.R., Parsons, B., Jackson, J.A., Shan, X., Sloan, R.A. \& Walker, R.T., 2011. Depth segmentation of the seismogenic continental crust: the 2008 and 2009 Qaidam earthquakes, Geophys. Res. Lett., 38, L06305.

Elliott, J.R. et al., 2015. The 2013 Mw 6.2 Khaki-Shonbe (Iran) earthquake: insights into seismic and aseismic shortening of the Zagros sedimentary cover, Earth Space Sci., 2(11), 435-471.

Ghods, A., Rezapour, M., Bergman, E., Mortezanejad, G. \& Talebian, M., 2012. Relocation of the $2006 \mathrm{Mw} 6.1$ Silakhour, Iran, earthquake sequence: details of fault segmentation on the main recent fault, Bull. seism. Soc. Am., 102, 398-416.

Havskov, J., Ottemöller, L. \& Voss, P., 2012, SEISAN: Earthquake Analysis Software, Version 9.1, Institute of Solid Earth Physics, University of Bergen, Norway

Jackson, J. \& McKenzie, D., 1984. Active tectonics of the Alpine-Himalayan Belt between western Turkey and Pakistan, Geophys. J. Int., 77, 185-264.

Jónsson, S., Zebker, H., Segall, P. \& Amelung, F., 2002. Fault slip distribution of the $1999 M_{w} 7.1$ Hector Mine, California, earthquake, estimated from satellite radar and GPS measurements, Bull. seism. Soc. Am., 92, 13771389.

Jordan, T.H. \& Sverdrup, K.A., 1981. Teleseismic location techniques and their application to earthquake clusters in the South-Central Pacific, Bull. seism. Soc. Am., 71, 1105-1130.

Karasözen, E., Nissen, E., Bergman, E.A., Johnson, K.L. \& Walters, R.J., 2016. Normal faulting in the Simav graben of western Turkey reassessed with calibrated earthquake relocations, J. geophys. Res., 121, 4553-4574.
Karasözen, E. et al., 2018. The 2017 July $20 M_{w} 6.6$ Bodrum-Kos earthquake illuminates active faulting in the Gulf of Gökova, SW Turkey, Geophys. J. Int., 214(1), 185-199.

Kennett, B.L.N., Engdahl, E.R. \& Buland, R., 1995. Constraints on seismic velocities in the Earth from traveltimes, Geophys. J. Int., 122, 108-124.

Kuo, Y.-T. et al., 2018. Shallow fault rupture of the Milun fault in the $2018 \mathrm{M}$ w 6.4 Hualien earthquake: a high-resolution approach from optical correlation of Pléiades satellite imagery, Seismol. Res. Lett., 90(1), 97-107.

Leprince, S., Barbot, S., Ayoub, F. \& Avouac, J.-P., 2007. Automatic and precise orthorectification, coregistration, and subpixel correlation of satellite images, application to ground deformation measurements, IEEE Trans. Geosci. Remote Sens., 45, 1529-1558.

Lohman, R.B. \& Barnhart, W.D., 2010. Evaluation of earthquake triggering during the 2005-2008 earthquake sequence on Qeshm Island, Iran, $J$. geophys. Res., 115, B12413.

Maggi, A., Jackson, J.A., Priestley, K. \& Baker, C., 2000. A re-assessment of focal depth distributions in southern Iran, the Tien Shan and northern India: do earthquakes really occur in the continental mantle?, Geophys. J. Int., 143, 629-661.

McCaffrey, R. \& Abers, G., 1988. SYN3: A Program for Inversion of Teleseismic Body Wave Forms on Microcomputers, Air Force Geophysical Laboratory Technical Report, Hanscomb Air Force Base, Massachusetts.

McCaffrey, R., Zwick, P. \& Abers, G., 1991. SYN4 Program, Tech. Rep., IASPEI Software Library.

Meyer, F.J., Arko, S.A., Hogenson, K., McAlpin, D.B. \& Whitley, M.B., 2017. A cloud-based system for automatic hazard monitoring from Sentinel-1 SAR datain AGU Fall Meeting Abstract, G33A-03, American Geophysical Union, New Orleans.

Milliner, C.W.D., Dolan, J.F., Hollingsworth, J., Leprince, S., Ayoub, F. \& Sammis, C.G., 2015. Quantifying near-field and off-fault deformation patterns of the $1992 \mathrm{M}_{w} 7.3$ Landers earthquake, Geochem. Geophys. Geosyst., 16, 1577-1598.

Molnar, P. \& Lyon-Caen, H., 1989. Fault plane solutions of earthquakes and active tectonics of the Tibetan Plateau and its margins, Geophys. J. Int., 99, 123-154.

Nemati, M., 2014. An appraisal of aftershocks behavior for large earthquakes in Persia, J. Asian Earth Sci., 79, 432-440.

Nemati, M. \& Gheitanchi, M.R., 2011. Analysis of 2005 Dahuieh (Zarand) aftershock sequences in Kerman province, southeast Iran, J. Earth Space Phys., 37(1), 1-9.

Nissen, E., Yamini-Fard, F., Tatar, M., Gholamzadeh, A., Bergman, E., Elliott, J.R., Jackson, J.A. \& Parsons, B., 2010. The vertical separation of mainshock rupture and microseismicity at Qeshm island in the Zagros Simply Folded Belt, Iran, Earth planet. Sci. Lett., 296, 181-194.

Nissen, E., Tatar, M., Jackson, J.A. \& Allen, M.B., 2011. New views on earthquake faulting in the Zagros fold-and-thrust belt of Iran, Geophys. J. Int., 186, 928-944.

Nissen, E., Jackson, J., Jahani, S. \& Tatar, M., 2014. Zagros "phantom earthquakes" reassessed - the interplay of seismicity and deep salt flow in the Simply Folded Belt?, J. geophys. Res., 119(4), 3561-3583.

Nissen, E. et al., 2019. The 12 November $2017 M_{w} 7.3$ Ezgeleh-Sarpolzahab (Iran) earthquake and active tectonics of the Lurestan arc, J. geophys. Res., 124, doi:10.1029/2018JB016221.

Okada, Y., 1985. Surface deformation due to shear and tensile faults in a half-space, Bull. seism. Soc. Am., 75, 1135-1154.

Penney, C. et al., 2017. Megathrust and accretionary wedge properties and behaviour in the Makran subduction zone, Geophys. J. Int., 209, 18001830.

Press, W.H., Teukolsky, S.A., Vetterling, W.T. \& Flannery, B.P., 1992. Numerical Recipes in C: The Art of Scientific Computing, Cambridge University Press.

Priestley, K., Baker, C. \& Jackson, J., 1994. Implications of earthquake focal mechanism data for the active tectonics of the south Caspian Basin and surrounding regions, Geophys. J. Int., 118, 111-141.

Roustaei, M. et al., 2010. The 25 March 2006 Fin earthquakes (Iran) insights into the vertical extents of faulting in the Zagros Simply Folded Belt, Geophys. J. Int., 181, 1275-1291. 
Simons, M., Fialko, Y. \& Rivera, L., 2002. Coseismic deformation from the $1999 \mathrm{Mw} 7.1$ Hector Mine, California, earthquake as inferred from InSAR and GPS observations, Bull. seism. Soc. Am., 92, 1390-1402.

Talebian, M. \& Jackson, J., 2004. A reappraisal of earthquake focal mechanisms and active shortening in the Zagros mountains of Iran, Geophys. J. Int., 156, 506-526.

Talebian, M. et al., 2006. The Dahuiyeh (Zarand) earthquake of 2005 February 22 in central Iran: reactivation of an intramountain reverse fault, Geophys. J. Int., 164, 137-148.

Talebian, M., Copley, A.C., Fattahi, M., Ghorashi, M., Jackson, J.A., Nazari, H., Sloan, R.A. \& Walker, R.T., 2016. Active faulting within a megacity: the geometry and slip rate of the Pardisan thrust in central Tehran, Iran, Geophys. J. Int., 207, 1688-1699.

Taymaz, T., Jackson, J. \& McKenzie, D., 1991. Active tectonics of the north and central Aegean Sea, Geophys. J. Int., 106, 433-490.

Vernant, P. et al., 2004. Present-day crustal deformation and plate kinematics in the Middle East constrained by GPS measurements in Iran and northern Oman, Geophys. J. Int., 157, 381-398.

Walker, R.T., 2006. A remote sensing study of active folding and faulting in southern Kerman province, S.E. Iran, J. Struct. Geol., 28, 654-668.

Walker, R. \& Jackson, J., 2004. Active tectonics and late Cenozoic strain distribution in central and eastern Iran, Tectonics, 23, TC5010.

Walker, R., Jackson, J. \& Baker, C., 2003. Surface expression of thrust faulting in eastern Iran: source parameters and surface deformation of the 1978 Tabas and 1968 Ferdows earthquake sequences, Geophys. J. Int., 152, 749-765.

Walker, R.T., Talebian, M., Saiffori, S., Sloan, R.A., Rasheedi, A., MacBean, N. \& Ghassemi, A., 2010. Active faulting, earthquakes, and restraining bend development near Kerman city in southeastern Iran, J. Struct. Geol., 32, 1046-1060.

Walker, R.T., Ramsey, L.A. \& Jackson, J., 2011. Geomorphic evidence for ancestral drainage patterns in the Zagros Simple Folded Zone and growth of the Iranian plateau, Geol. Mag., 148, 901-910.

Wells, D.L. \& Coppersmith, K.J., 1994. New empirical relationships among magnitude, rupture length, rupture width, rupture area, and surface displacement, Bull. seism. Soc. Am., 84(4), 974-1002.

Wessel, P., Smith, W.H.F., Scharroo, R., Luis, J. \& Wobbe, F., 2013. Generic mapping tools: improved version released, Eos, Trans. Am. geophys. Un., 94, 409-410.

Wright, T.J., Parsons, B.E., Jackson, J.A., Haynes, M., Fielding, E.J., England, P.C. \& Clarke, P.J., 1999. Source parameters of the 1 October 1995 Dinar (Turkey) earthquake from SAR interferometry and seismic bodywave modelling, Earth planet. Sci. Lett., 172, 23-37.

Wright, T.J., Lu, Z. \& Wicks, C., 2003. Source model for the $M_{w} 6.7$, 23 October 2002, Nenana Mountain Earthquake (Alaska) from InSAR, Geophys. Res. Lett., 30(18), 1974.

Zinke, R., Hollingsworth, J., Dolan, J.F. \& Van Dissen, R., 2019. 3D surface deformation in the $2016 \mathrm{Mw} 7.8$ Kaikōura, New Zealand earthquake from optical image correlation: Implications for strain localization and long-term evolution of the Pacific-Australian plate boundary, Geochem. Geophys. Geosyst., in press.

Zwick, P., McCaffrey, R. \& Abers, G., 1994. MT5 Program , IASPEI Software Library 4.

\section{SUPPORTING INFORMATION}

Supplementary data are available at $G J I$ online.

Figure S1: Ray paths used in direct calibration of the cluster hypocentroid (red lines), seismic stations (blue triangles), Building and House Research Center of Iran (BHRC) accelerometer stations (yellow diamonds) and relocated earthquakes (black circles).

Figure S2: Relocated, calibrated epicentres of the Hojedk sequence, coloured by date and with 90 per cent confidence ellipses in absolute location. Black lines show shift vectors from initial starting epicentres (taken from the Bulletin of the International Seismological Centre) to final calibrated epicentres. The three mains hocks E1-E3 are labelled and plotted with their body waveform modelling focal mechanisms.

Figure S3: Fit between observed phase arrivals (symbols) and theoretical traveltimes (lines) over the epicentral distance range $0^{\circ}-4^{\circ}$. Phase arrivals are distinguished as $P g$ (red crosses), $S g$ (red circles), $P n$ (green crosses), $S n$ (green circles) and $L g$ (blue circles). The vertical dashed line shows the distance limit used for the hypocentroid calculation.

Figure S4: Aftershock mechanisms from $P$ wave first motion polarities in a lower hemisphere projection. Individual polarities are marked + for first motion up and - for first motion down. $P$ and $T$ axes are labelled with coloured letters.

Figure S5: (a) Data, (b) model and (c) residual interferograms of ascending track 57A spanning the first main shock, E1, showing the alternative, SW-dipping fault model (strike $122^{\circ}$, dip $39^{\circ}$, rake $90^{\circ}$ ). $i$ is the radar incidence angle measured from the vertical in the epicentral region, and $2 \pi$ radians in wrapped phase is equal to $5.55 \mathrm{~cm}$ in line-of-sight displacement. In (b) and (c), the thick black line is the surface projection of the initial uniform slip model fault, and thin lines show $0.2 \mathrm{~m}$ slip contours of the variable slip model. The focal mechanism is our seismological body-waveform model, plotted at its relocated epicentre. (d) Data, (e) model and (f) residual interferograms for ascending track 159A, $(g-i)$ for descending track $93 \mathrm{D}$ and $(\mathrm{j}-1)$ for descending track $166 \mathrm{D}$.

Figure S6: Data, model and residual interferograms for the second (E2) and third (E3) main shocks, showing the alternative SWdipping E2 model fault with strike, dip and rake fixed to $130^{\circ}, 36^{\circ}$ and $89^{\circ}$, respectively (see main text). The southern E2 and northern E3 slip contours are plotted at 0.1 and $0.5 \mathrm{~m}$ increments, respectively. The E2 body waveform focal mechanism is in yellow and the E3 mechanism is in blue.

Table S1: Calibrated epicentres of all earthquakes included in the Hodejk cluster. Focal depth is in kilometres, with superscript codes that describe the source of the depth constraint: $w$ for waveform analysis, $n$ for near-source station readings $\left(<0.25^{\circ}\right.$ epicentral distance), $l$ for local-source station readings $\left(>0.25^{\circ}\right)$ and $c$ for fixed, cluster-default solutions. A1 is the azimuth of the major axis of the 90 per cent confidence ellipse in degrees clockwise from north, L1 and L2 are its semi-minor and semi-major axis lengths in kilometres, and Area is that of the 90 percent confidence ellipse in $\mathrm{km}^{2}$. The three main shocks E1, E2 and E3 are highlighted in bold.

Please note: Oxford University Press are not responsible for the content or functionality of any supporting materials supplied by the authors. Any queries (other than missing material) should be directed to the corresponding author for the paper. 


\title{
Supporting Information for "The December 2017 Hojedk
}

\section{(Iran) earthquake triplet - sequential rupture of shallow} reverse faults in a strike-slip restraining bend"

\author{
Elena Savidge, Edwin Nissen*, Majid Nemati, Ezgi Karasözen, \\ James Hollingsworth, Morteza Talebian, Eric Bergman, Abdolreza Ghods, \\ Manouchehr Ghorashi, Ehsan Kosari, Ahmad Rashidi and Ali Rashidi \\ *Corresponding Author E-mail: enissen@uvic.ca \\ School of Earth and Ocean Sciences, University of Victoria, Victoria, BC, Canada
}

Accepted 2019 January 14; Received 2019 January 14; in original form 2018 August 18

(i) Figure S1: ray paths used in direct calibration of the Hojedk cluster hypocentroid

(ii) Figure S2: relocated, calibrated epicenters of Hojedk sequence

(iii) Figure S3: fit between observed phase arrivals and theoretical traveltimes

(iv) Figure S4: aftershock mechanisms from first motion polarities

(v) Figure S5: data, model and residual interferograms for E1, assuming a SW-dipping model fault

(vi) Figure S6: data, model and residual interferograms for E2 and E3, assuming a SW-dipping E2 model fault

(vii) Table S1: calibrated earthquake relocations 


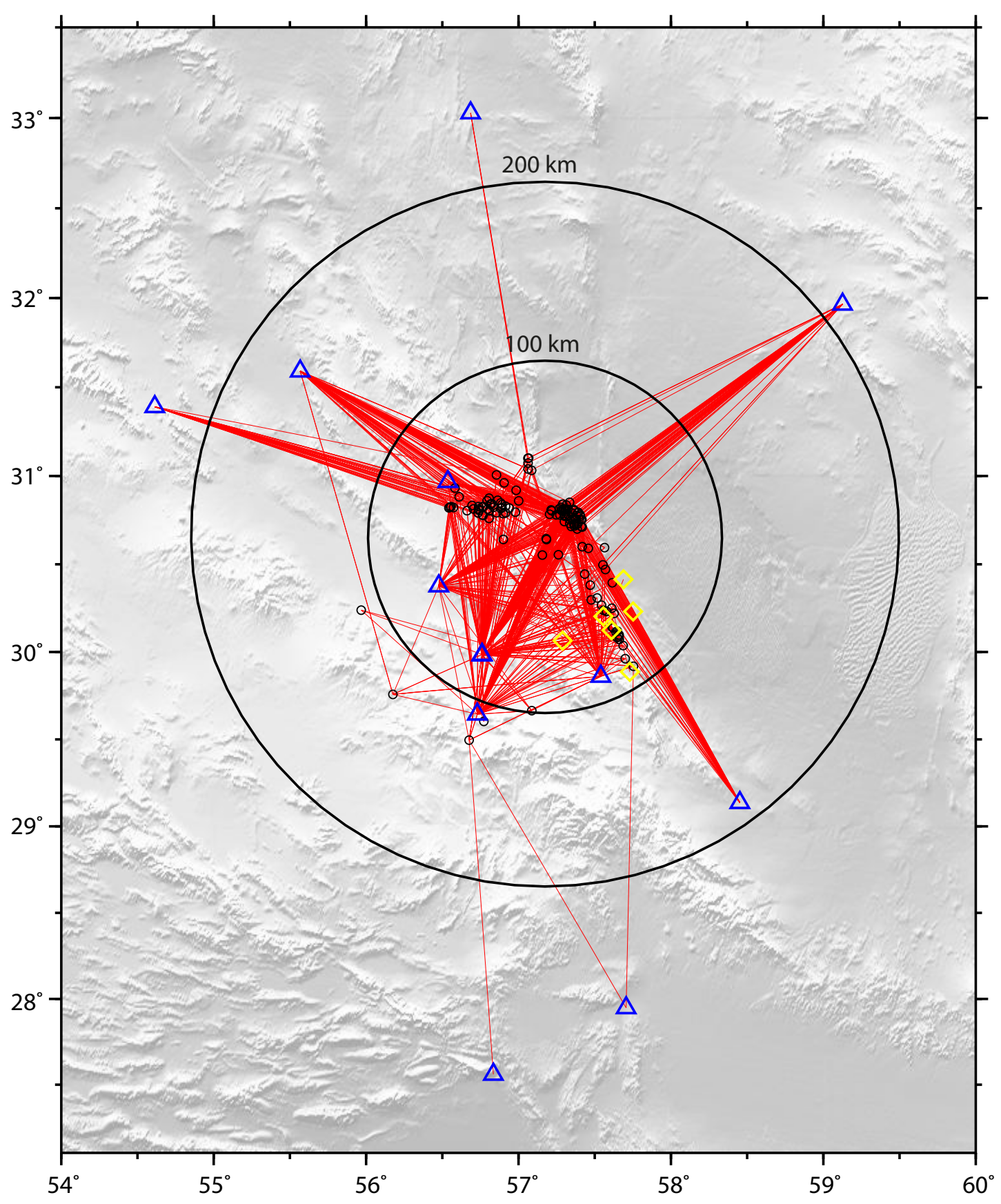

Figure S1. Ray paths used in direct calibration of the cluster hypocentroid (red lines), seismic stations (blue triangles), Building and House Research Center of Iran (BHRC) accelerometer stations (yellow diamonds), and relocated earthquakes (black circles). 


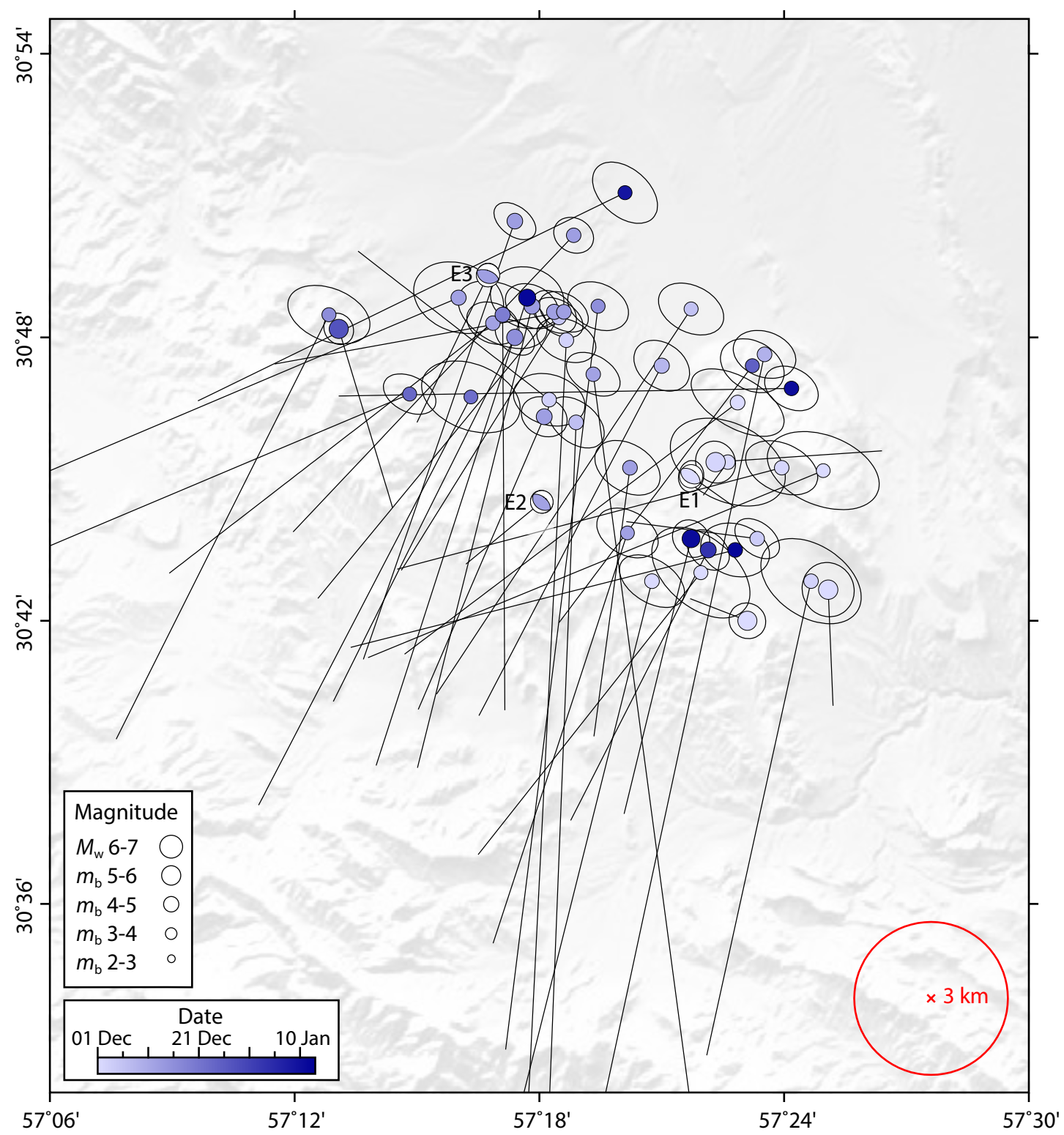

Figure S2. Relocated, calibrated epicenters of the Hojedk sequence, colored by date and with $90 \%$ confidence ellipses in absolute location. Black lines show shift vectors from initial starting epicenters (taken from the Bulletin of the International Seismological Centre) to final calibrated epicenters. The three mainshocks E1-E3 are labelled and plotted with their body waveform modelling focal mechanisms. 


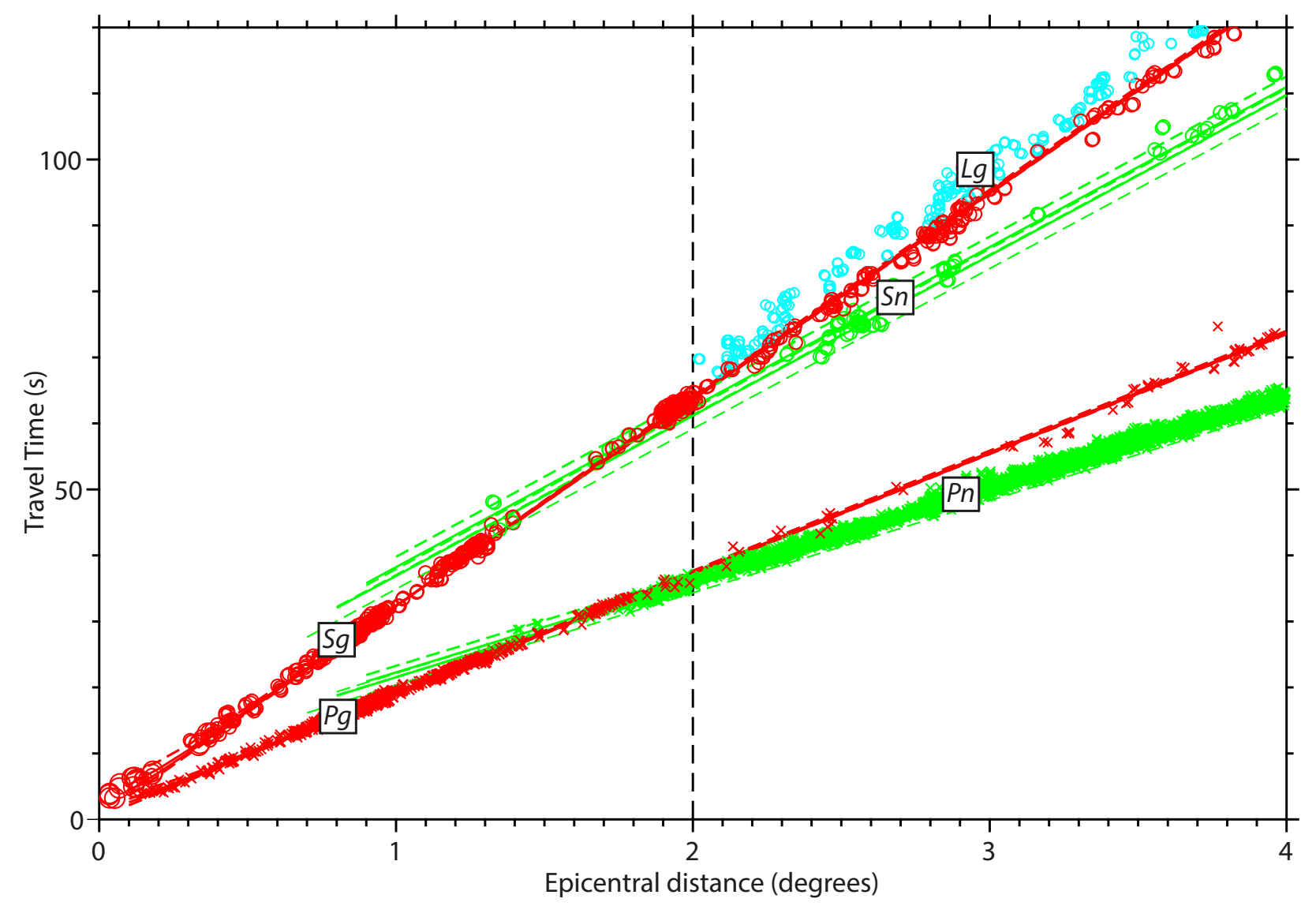

Figure S3. Fit between observed phase arrivals (symbols) and theoretical traveltimes (lines) over the epicentral distance range $0^{\circ}-4^{\circ}$. Phase arrivals are distinguished as $\mathrm{Pg}$ (red crosses), $\mathrm{Sg}$ (red circles), $\mathrm{Pn}$ (green crosses), $S n$ (green circles) and $L g$ (blue circles). The vertical dashed line shows the distance limit used for the hypocentroid calculation. 

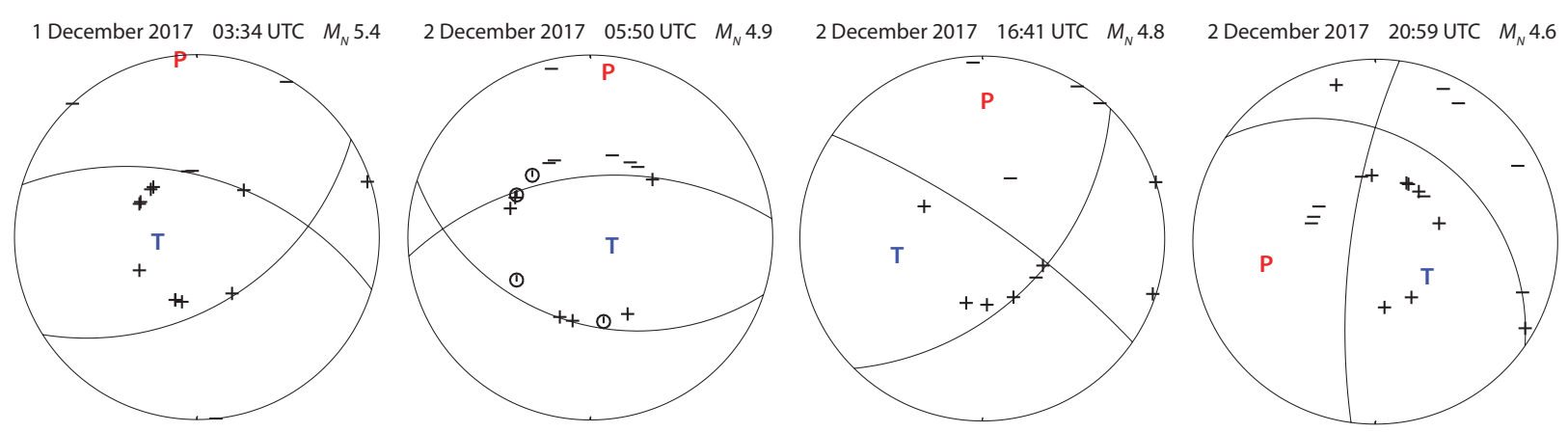

3 December 2017 02:47 UTC $M_{N} 5.0$

4 December 2017 02:58 UTC $M_{N} 4.8$

5 December 2017 09:23 UTC $M_{N} 4.9$

9 December $2017 \quad$ 07:42 UTC $M_{N} 4.8$
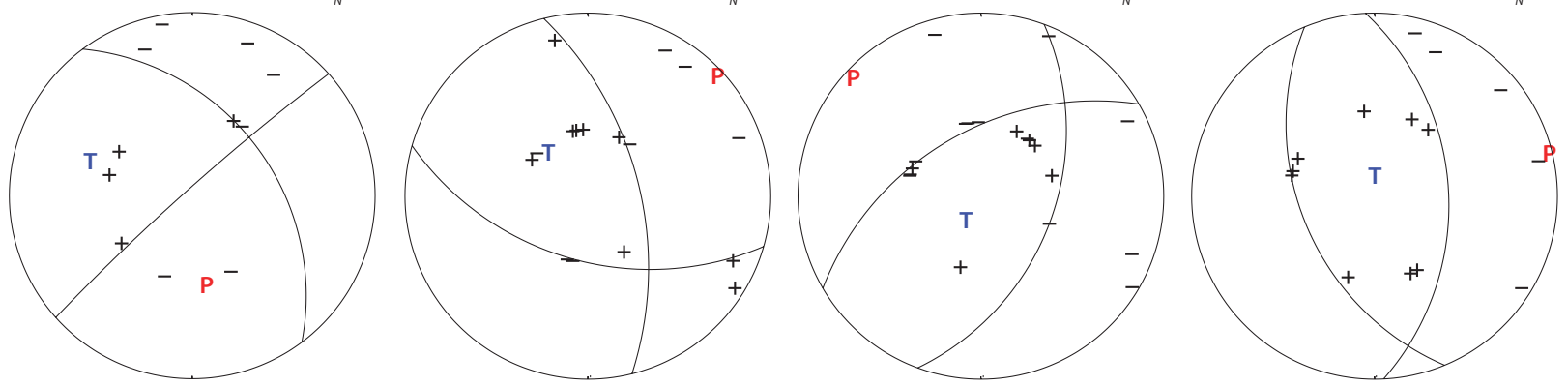

13 December 2017 04:03 UTC $M_{N} 5.1$

13 December 2017 09:51 UTC $M_{N} 5.0$

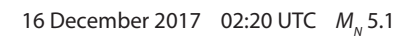

25 December 2017 03:34 UTC $M_{N} 4.7$
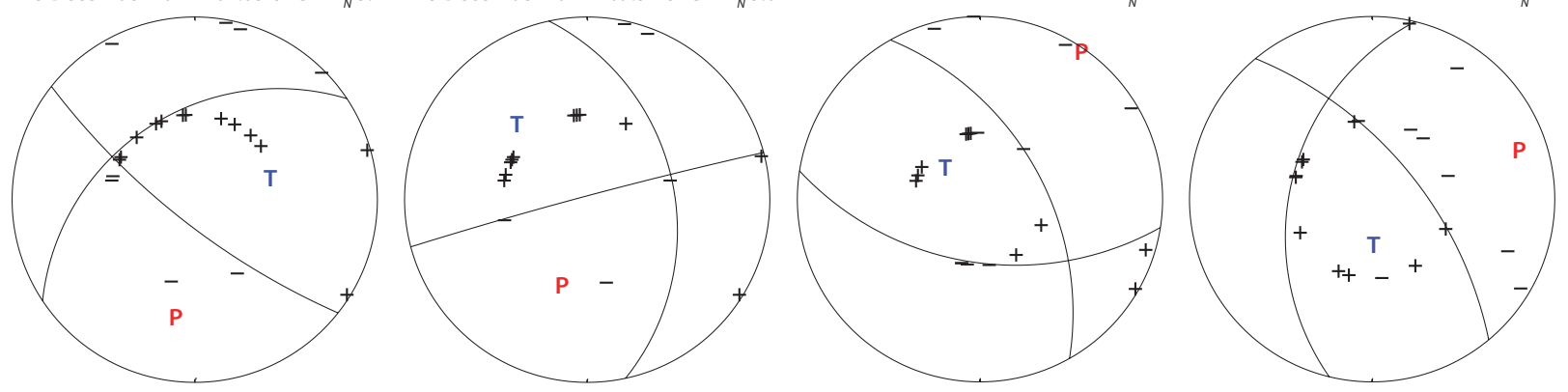

27 December $2017 \quad$ 18:01 UTC $M_{N} 5.5$

3 January $2018 \quad 04: 13$ UTC $M_{N} 5.1$

10 January $2018 \quad$ 17:10 UTC $M_{N} 4.6$

11 January $2018 \quad$ 13:35 UTC $\quad M_{N} 5.3$
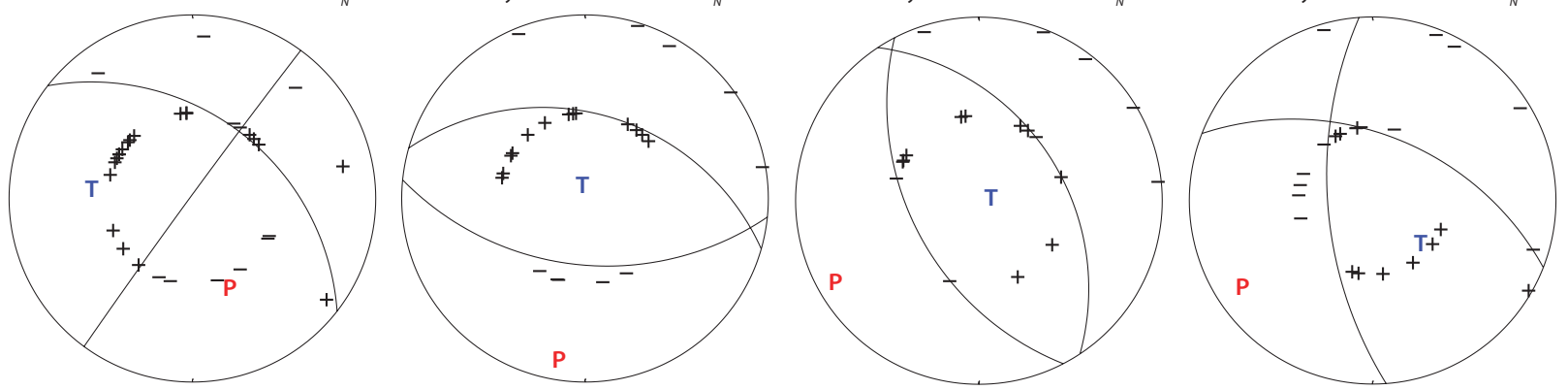

Figure S4. Aftershock mechanisms from $P$ wave first motion polarities in a lower hemisphere projection.

Individual polarities are marked + for first motion up and - for first motion down. $\mathrm{P}$ and $\mathrm{T}$ axes are labelled with coloured letters. 

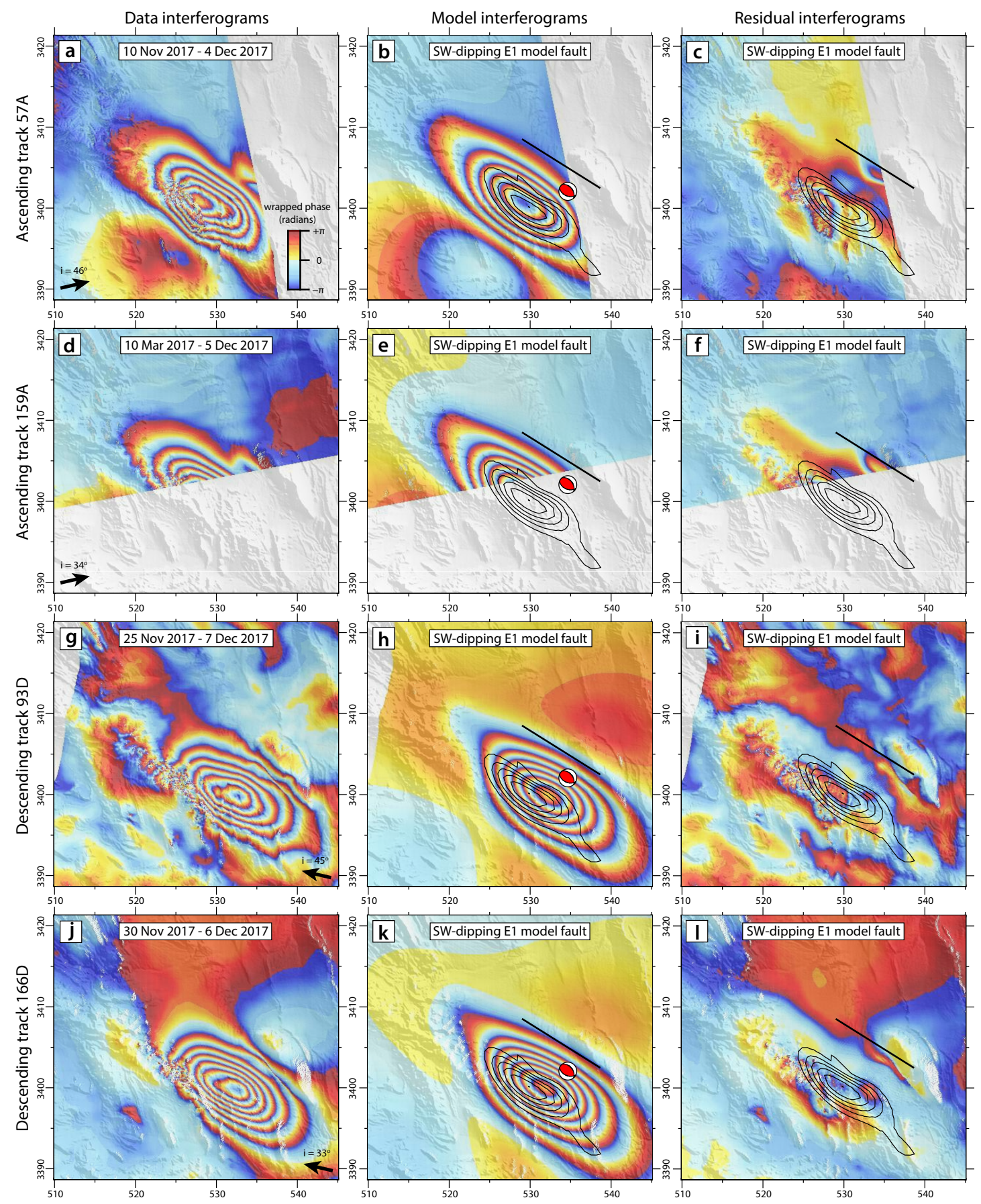

Figure S5. (a) Data, (b) model and (c) residual interferograms of ascending track 57A spanning the first mainshock, E1, showing the alternative, SW-dipping fault model (strike $122^{\circ}$, dip $39^{\circ}$, rake $90^{\circ}$ ). $i$ is the radar incidence angle measured from the vertical in the epicentral region, and $2 \pi$ radians in wrapped phase is equal to $5.55 \mathrm{~cm}$ in line-of-sight displacement. In (b) and (c), the thick black line is the surface projection of the initial uniform slip model fault, and thin lines show $0.2 \mathrm{~m}$ slip contours of the variable slip model. The focal mechanism is our seismological body-waveform model, plotted at its relocated epicenter. (d) Data, (e) model and (f) residual interferograms for ascending track 159A, $(\mathrm{g}-\mathrm{i})$ for descending track 93D, and $(\mathrm{j}-\mathrm{l})$ for descending track 166D. 

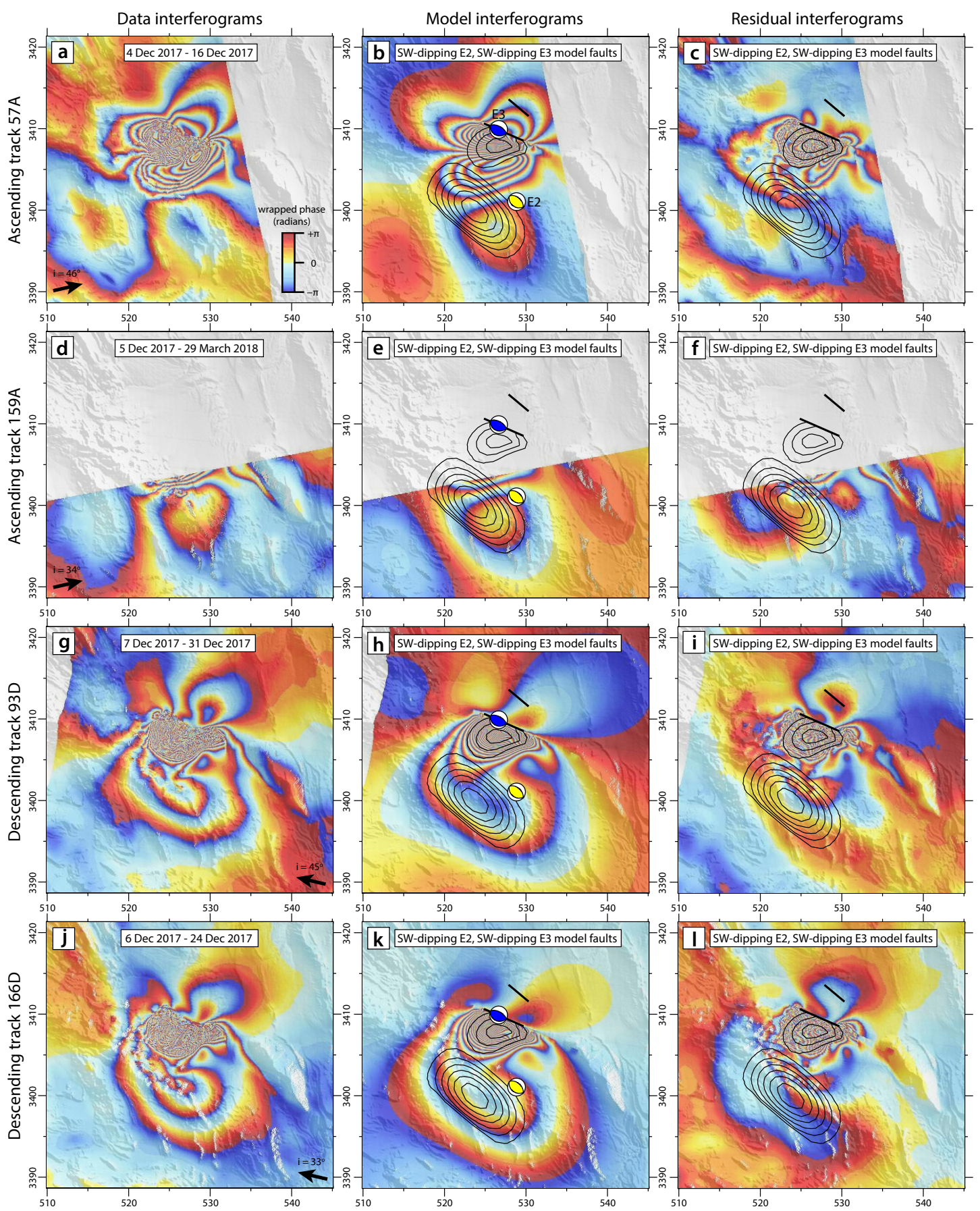

Figure S6. Data, model and residual interferograms for the second (E2) and third (E3) mainshocks, showing the alternative SW-dipping E2 model fault with strike, dip and rake fixed to $130^{\circ}, 36^{\circ}$ and $89^{\circ}$, respectively (see main text). The southern E2 and northern E3 slip contours are plotted at $0.1 \mathrm{~m}$ and $0.5 \mathrm{~m}$ increments, respectively. The E2 body waveform focal mechanism is in yellow and the E3 mechanism is in blue. 
Table S1. Calibrated epicenters of all earthquakes included in the Hodejk cluster. Focal depth is in kilometers, with superscript codes that describe the source of the depth constraint: $w$ for waveform analysis, $n$ for near-source station readings $\left(<0.25^{\circ}\right.$ epicentral distance $), l$ for local-source station readings $\left(>0.25^{\circ}\right)$ and $c$ for fixed, cluster-default solutions. A1 is the azimuth of the major axis of the $90 \%$ confidence ellipse in degrees clockwise from north, L1 and L2 are its semi-minor and semi-major axis lengths in kilometers, and Area is that of the $90 \%$ confidence ellipse in $\mathrm{km}^{2}$. The three mainshocks E1, E2 and E3 are highlighted in bold.

\begin{tabular}{rrrrrrrrrr}
\hline Date & Time & Lat. & Lon. & Depth & Mag. & A1 & L1 & L2 & Area \\
\hline 2005.02 .22 & $02: 25: 21.4$ & 30.803 & 56.808 & $14^{w}$ & $6.4 M_{w}$ & 346 & 1.0 & 1.4 & 4.2 \\
2005.02 .22 & $05: 08: 29.2$ & 30.816 & 56.884 & $10^{c}$ & 4.3 & 354 & 1.3 & 1.8 & 7.2 \\
2005.02 .22 & $05: 26: 47.4$ & 30.823 & 56.837 & $10^{c}$ & 4.6 & 341 & 1.4 & 1.9 & 8.4 \\
2005.02 .24 & $08: 39: 33.1$ & 30.779 & 56.764 & $10^{c}$ & 3.6 & 351 & 1.7 & 2.7 & 14.1 \\
2005.02 .24 & $23: 26: 30.9$ & 30.814 & 56.704 & $10^{c}$ & 4.2 & 349 & 1.6 & 2.2 & 10.8 \\
2005.02 .25 & $01: 11: 59.1$ & 30.777 & 56.768 & $10^{c}$ & 4.4 & 350 & 1.3 & 1.9 & 7.4 \\
2005.02 .25 & $19: 54: 14.7$ & 30.760 & 56.807 & $10^{c}$ & 3.8 & 352 & 1.7 & 2.6 & 13.6 \\
2005.02 .27 & $13: 20: 43.3$ & 30.844 & 56.822 & $10^{c}$ & 4 & 348 & 1.4 & 1.8 & 7.6 \\
2005.03 .01 & $16: 13: 45.2$ & 30.838 & 56.892 & $10^{c}$ & 4.4 & 343 & 1.4 & 1.8 & 7.9 \\
2005.03 .03 & $00: 50: 03.4$ & 30.819 & 56.940 & $10^{c}$ & 4.6 & 348 & 1.5 & 1.9 & 9 \\
2005.03 .04 & $03: 42: 40.3$ & 30.791 & 56.734 & $10^{c}$ & 4.1 & 335 & 1.4 & 2.3 & 9.7 \\
2005.03 .05 & $16: 04: 19.4$ & 30.115 & 57.639 & $10^{c}$ & 3.4 & 6 & 2.5 & 2.9 & 23 \\
\hline
\end{tabular}


Table S1 (Continued)

\begin{tabular}{|c|c|c|c|c|c|c|c|c|c|}
\hline Date & Time & Lat. & Lon. & Depth & Mag. & A1 & L1 & $\mathrm{L} 2$ & Area \\
\hline 2005.03 .19 & 01:29:55.2 & 30.805 & 56.742 & $10^{c}$ & 3.8 & 349 & 1.7 & 2.7 & 14.3 \\
\hline 2005.05 .01 & $18: 58: 38.5$ & 30.795 & 56.980 & $10^{c}$ & 4.9 & 341 & 1.2 & 1.5 & 5.4 \\
\hline 2005.05 .01 & $19: 43: 30.7$ & 30.821 & 56.892 & $10^{c}$ & 4.2 & 349 & 1.4 & 1.9 & 8.4 \\
\hline 2005.05 .12 & $22: 55: 05.9$ & 30.641 & 56.900 & $10^{c}$ & 4.6 & 347 & 1.4 & 1.9 & 8.1 \\
\hline 2005.05 .14 & 18:04:54.1 & 30.791 & 56.915 & $10^{c}$ & 5.5 & 349 & 1.0 & 1.4 & 4.1 \\
\hline 2005.05 .18 & $00: 18: 12.8$ & 30.833 & 56.695 & $10^{c}$ & 4.1 & 340 & 1.8 & 2.3 & 12.9 \\
\hline 2005.09.05 & 05:00:14.2 & 30.860 & 56.794 & $10^{c}$ & 4 & 358 & 1.7 & 2.6 & 13.4 \\
\hline 2005.11 .20 & $16: 11: 05.4$ & 30.863 & 56.863 & $10^{c}$ & 3.7 & 350 & 1.8 & 2.8 & 16.1 \\
\hline 2006.03.07 & 02:18:58.8 & 30.829 & 56.915 & $10^{c}$ & 3.9 & 347 & 1.5 & 2.2 & 9.9 \\
\hline 2006.05.07 & $06: 20: 52.8$ & 30.804 & 56.662 & $10^{c}$ & 4.8 & 342 & 1.1 & $\mathrm{~s} 1.5$ & 5.2 \\
\hline 2006.06.04 & $16: 18: 24.7$ & 30.444 & 57.435 & $10^{c}$ & 4 & 3 & 1.4 & 1.7 & 7.6 \\
\hline 2006.06.07 & 20:57:29.1 & 30.843 & 56.824 & $10^{c}$ & 3.9 & 340 & 1.4 & 1.7 & 7.7 \\
\hline 2006.08.31 & $02: 28: 26.6$ & 30.395 & 57.615 & $10^{c}$ & 4.2 & 36 & 1.6 & 2.2 & 11.4 \\
\hline 2006.10.09 & $07: 43: 52.4$ & 30.826 & 56.764 & $10^{c}$ & 4.4 & 354 & 1.1 & 1.6 & 5.5 \\
\hline 2006.12.08 & $07: 58: 33.5$ & 30.882 & 56.610 & $10^{c}$ & 4.5 & 350 & 1.1 & 1.6 & 5.6 \\
\hline 2006.12 .13 & $13: 32: 04.2$ & 30.594 & 57.565 & $10^{c}$ & 4.4 & 16 & 1.4 & 1.9 & 8.2 \\
\hline 2007.02.19 & $02: 45: 49.6$ & 30.847 & 56.883 & $10^{c}$ & 4.6 & 280 & 2.0 & 3.0 & 18.6 \\
\hline 2007.04.01 & $19: 51: 23.4$ & 30.813 & 56.797 & $10^{c}$ & 4.2 & 309 & 1.6 & 2.3 & 11.3 \\
\hline 2007.04 .08 & $11: 22: 19.5$ & 31.006 & 56.856 & $10^{c}$ & 4.2 & 360 & 1.5 & 2.1 & 10.1 \\
\hline 2008.02.27 & 01:58:23.5 & 30.787 & 56.899 & $10^{c}$ & 3.8 & 2 & 1.8 & 2.4 & 13.6 \\
\hline 2008.05.27 & $17: 07: 17.7$ & 30.640 & 57.184 & $10^{c}$ & 3.9 & 27 & 1.6 & 2.3 & 11.3 \\
\hline 2008.06.04 & $00: 38: 40.4$ & 30.238 & 57.558 & $11^{n}$ & 3.8 & 50 & 2.1 & 3.7 & 24.8 \\
\hline 2009.02 .15 & 21:22:17.1 & 31.039 & 57.063 & $10^{c}$ & $4.7 m_{b}$ & 354 & 1.0 & 1.4 & 4.7 \\
\hline 2009.03.02 & 01:04:37.3 & 30.599 & 57.418 & $10^{c}$ & $3.6 m_{b}$ & 1 & 1.4 & 2.1 & 9.1 \\
\hline 2009.03.07 & $06: 47: 06.8$ & 30.826 & 56.770 & $10^{c}$ & $4 m_{b}$ & 345 & 1.2 & 1.7 & 6.1 \\
\hline
\end{tabular}


Table S1 (Continued)

\begin{tabular}{|c|c|c|c|c|c|c|c|c|c|}
\hline Date & Time & Lat. & Lon. & Depth & Mag. & A1 & L1 & L2 & Area \\
\hline 2009.05 .11 & 02:14:03.7 & 30.250 & 57.612 & $21^{n}$ & $4.1 m_{b}$ & 357 & 1.3 & 1.6 & 6.8 \\
\hline 2009.05 .12 & $06: 30: 48.8$ & 30.083 & 57.647 & $9^{n}$ & $3.8 m_{b}$ & 39 & 2.1 & 3.6 & 23.2 \\
\hline 2009.10.21 & 01:44:36.1 & 30.098 & 57.660 & $10^{c}$ & $3.4 m_{b}$ & 22 & 1.7 & 2.5 & 13.3 \\
\hline 2009.10.27 & $17: 19: 33.5$ & 30.874 & 56.807 & $10^{c}$ & $3.9 m_{b}$ & 353 & 1.9 & 2.1 & 12.6 \\
\hline 2010.01.26 & 03:16:59.9 & 30.859 & 57.001 & $10^{c}$ & $4 m_{b}$ & 2 & 1.2 & 1.8 & 6.9 \\
\hline 2010.07.31 & $06: 52: 55.1$ & 29.603 & 56.773 & $12^{l}$ & $5.4 m_{b}$ & 347 & 1.0 & 1.4 & 4.6 \\
\hline 2010.09.15 & $19: 57: 57.4$ & 30.839 & 56.814 & $11^{l}$ & $4.2 m_{b}$ & 1 & 1.0 & 1.6 & 5.3 \\
\hline 2010.11 .24 & $00: 38: 35.0$ & 30.814 & 56.737 & $12^{l}$ & $3.8 m_{b}$ & 353 & 1.1 & 1.6 & 5.2 \\
\hline 2011.01 .09 & $18: 11: 02.4$ & 30.297 & 57.477 & $13^{l}$ & $3.7 m_{b}$ & 21 & 1.4 & 1.9 & 8.7 \\
\hline 2011.04 .30 & 08:55:11.1 & 30.804 & 57.366 & $10^{c}$ & $3.7 m_{b}$ & 10 & 1.4 & 2.6 & 11 \\
\hline 2011.06.26 & $19: 46: 55.9$ & 30.119 & 57.649 & $12^{l}$ & $5 m_{b}$ & 355 & 1.1 & 1.4 & 4.8 \\
\hline 2011.12.16 & $21: 10: 45.7$ & 30.827 & 56.738 & $9^{l}$ & $4 m_{b}$ & 3 & 1.2 & 1.8 & 6.9 \\
\hline 2012.12 .03 & $12: 53: 23.3$ & 30.554 & 57.262 & $12^{l}$ & $4.6 m_{b}$ & 0 & 1.0 & 1.5 & 4.4 \\
\hline 2012.12.13 & $22: 03: 38.0$ & 30.239 & 55.968 & $13^{l}$ & & 355 & 1.2 & 2.0 & 7.4 \\
\hline 2013.01.06 & $15: 24: 13.9$ & 30.267 & 57.545 & $7^{l}$ & $4 m_{b}$ & 11 & 1.2 & 1.9 & 7.1 \\
\hline 2013.01 .21 & $19: 48: 57.0$ & 30.381 & 57.471 & $7^{l}$ & $5.2 m_{b}$ & 354 & 0.9 & 1.4 & 3.8 \\
\hline 2013.02.22 & 01:39:23.2 & 29.665 & 57.087 & $11^{l}$ & $4.2 m_{b}$ & 359 & 1.2 & 1.7 & 6.3 \\
\hline 2013.08 .25 & $13: 56: 31.6$ & 30.645 & 57.182 & $8^{l}$ & $4.3 m_{b}$ & 357 & 1.0 & 1.5 & 4.5 \\
\hline 2013.11.12 & $02: 27: 23.6$ & 30.552 & 57.156 & $9^{l}$ & $3.6 m_{b}$ & 16 & 1.2 & 1.7 & 6.7 \\
\hline 2013.12 .26 & $00: 44: 24.6$ & 30.308 & 57.516 & $8^{l}$ & $3.7 m_{b}$ & 11 & 1.2 & 1.8 & 6.8 \\
\hline 2014.01.11 & $19: 05: 29.1$ & 29.496 & 56.676 & $14^{n}$ & & 6 & 1.3 & 2.5 & 10 \\
\hline 2014.02 .15 & $18: 57: 20.4$ & 30.590 & 57.458 & $8^{l}$ & $3.5 m_{b}$ & 10 & 1.2 & 1.8 & 6.7 \\
\hline 2014.04 .05 & $12: 16: 30.3$ & 30.932 & 56.583 & $9^{l}$ & $4 m_{b}$ & 359 & 1.4 & 2.1 & 9.3 \\
\hline 2014.04.11 & $23: 36: 12.8$ & 30.961 & 56.905 & $13^{l}$ & $3.5 m_{b}$ & 4 & 1.3 & 2.0 & 7.8 \\
\hline 2014.05 .10 & $13: 36: 38.6$ & 29.758 & 56.176 & $14^{l}$ & $3.2 M_{L}$ & 341 & 1.6 & 2.0 & 9.6 \\
\hline
\end{tabular}


Table S1 (Continued)

\begin{tabular}{|c|c|c|c|c|c|c|c|c|c|}
\hline Date & Time & Lat. & Lon. & Depth & Mag. & A1 & L1 & L2 & Area \\
\hline 2014.06.03 & 09:50:34.1 & 29.962 & 57.700 & $13^{n}$ & $3.6 M_{L}$ & 57 & 1.6 & 2.3 & 11.7 \\
\hline 2014.09.16 & $17: 25: 26.8$ & 30.220 & 57.627 & $13^{l}$ & $3.7 m_{b}$ & 9 & 1.3 & 1.6 & 6.5 \\
\hline 2014.09.22 & $06: 26: 05.2$ & 30.783 & 57.204 & $10^{l}$ & $4 M_{L}$ & 18 & 1.2 & 2.0 & 7.3 \\
\hline 2014.09.30 & $22: 43: 59.3$ & 29.919 & 57.754 & $14^{n}$ & $3.6 M_{L}$ & 46 & 1.8 & 2.2 & 12.2 \\
\hline 2014.12.12 & 04:10:43.5 & 30.496 & 57.554 & $14^{l}$ & $3.2 M_{L}$ & 23 & 1.5 & 1.9 & 8.9 \\
\hline 2015.02.13 & 01:00:44.0 & 30.231 & 57.578 & $5^{l}$ & $3.8 m_{b}$ & 7 & 1.1 & 1.6 & 5.8 \\
\hline 2015.02.17 & $13: 41: 35.7$ & 30.037 & 57.687 & $6^{n}$ & $4.2 m_{b}$ & 359 & 1.0 & 1.4 & 4.4 \\
\hline 2015.07.25 & $16: 10: 41.0$ & 30.096 & 57.657 & $10^{l}$ & $4.3 m_{b}$ & 3 & 1.2 & 1.5 & 5.4 \\
\hline 2015.07.31 & 10:06:29.4 & 30.072 & 57.661 & $11^{l}$ & $5.2 m_{b}$ & 353 & 0.9 & 1.3 & 3.8 \\
\hline 2015.08.21 & $01: 21: 16.3$ & 30.086 & 57.659 & $10^{l}$ & $4 M_{L}$ & 25 & 1.5 & 1.7 & 8 \\
\hline 2015.08.26 & $13: 20: 25.6$ & 30.919 & 56.984 & $9^{l}$ & $4.1 M_{L}$ & 3 & 1.1 & 1.7 & 5.8 \\
\hline 2015.12 .24 & $12: 02: 16.2$ & 31.101 & 57.066 & $10^{c}$ & $4.3 M_{L}$ & 3 & 1.2 & 1.9 & 6.7 \\
\hline 2015.12 .31 & 03:50:31.1 & 31.073 & 57.063 & $19^{l}$ & $3.9 m_{b}$ & 359 & 1.1 & 1.7 & 5.8 \\
\hline 2015.12.31 & 05:30:11.4 & 31.100 & 57.062 & $10^{c}$ & $4.2 M_{L}$ & 4 & 1.1 & 1.8 & 6.1 \\
\hline 2016.02.11 & $00: 43: 22.1$ & 30.824 & 56.550 & $11^{l}$ & $3.8 M_{L}$ & 353 & 1.1 & 1.8 & 6.1 \\
\hline 2016.06.04 & 09:54:14.3 & 30.138 & 57.620 & $10^{l}$ & $4.1 m_{b}$ & 7 & 1.1 & 1.5 & 5 \\
\hline 2016.06.17 & 10:03:46.6 & 30.234 & 57.575 & $6^{l}$ & $4.4 m_{b}$ & 2 & 1.0 & 1.5 & 4.8 \\
\hline 2016.09.02 & 09:48:54.0 & 31.032 & 57.086 & $10^{c}$ & $3.6 M_{L}$ & 7 & 1.3 & 2.2 & 8.6 \\
\hline 2016.10 .20 & 15:10:29.1 & 30.821 & 56.573 & $10^{l}$ & $4.9 M_{L}$ & 353 & 0.9 & 1.4 & 3.8 \\
\hline 2016.10.26 & $19: 12: 46.1$ & 30.792 & 56.856 & $10^{l}$ & $3.8 M_{L}$ & 1 & 0.9 & 1.5 & 4.4 \\
\hline 2016.10 .28 & $14: 02: 26.4$ & 30.820 & 56.543 & $13^{l}$ & $4.7 M_{L}$ & 355 & 0.9 & 1.4 & 3.7 \\
\hline 2016.10.31 & $13: 43: 59.8$ & 30.826 & 56.558 & $8^{n}$ & $4.5 M_{L}$ & 354 & 0.9 & 1.5 & 4.2 \\
\hline 2016.12.01 & 09:21:42.6 & 30.470 & 57.570 & $13^{l}$ & $4.5 m_{b}$ & 1 & 1.0 & 1.5 & 4.3 \\
\hline 2017.07.23 & $17: 32: 12.3$ & 30.143 & 57.613 & $10^{l}$ & $5 m_{b}$ & 358 & 1.0 & 1.3 & 4.4 \\
\hline 2017.09.20 & 00:08:13.9 & 30.753 & 57.410 & $10^{l}$ & $4.4 m_{b}$ & 358 & 1.0 & 1.5 & 4.7 \\
\hline
\end{tabular}


Table S1 (Continued)

\begin{tabular}{|c|c|c|c|c|c|c|c|c|c|}
\hline Date & Time & Lat. & Lon. & Depth & Mag. & A1 & L1 & L2 & Area \\
\hline 2017.09.21 & $19: 28: 38.5$ & 30.772 & 57.405 & $7^{l}$ & $4.1 m_{b}$ & 3 & 1.0 & 1.4 & 4.5 \\
\hline 2017.12.01 & $02: 32: 44.1$ & 30.751 & 57.362 & $12^{l}$ & 6.1 $M_{w}$ & 351 & 0.9 & 1.3 & 3.8 \\
\hline 2017.12.01 & $02: 43: 25.2$ & 30.700 & 57.385 & $11^{l}$ & $5 m_{b}$ & 355 & 1.0 & 1.4 & 4.3 \\
\hline 2017.12.01 & $02: 57: 47.9$ & 30.777 & 57.381 & $10^{l}$ & $3.9 m_{b}$ & 22 & 1.3 & 2.3 & 9.5 \\
\hline 2017.12.01 & 03:34:59.0 & 30.711 & 57.418 & $6^{l}$ & $5.1 m_{b}$ & 356 & 1.3 & 1.6 & 6.3 \\
\hline 2017.12.01 & 03:51:30.1 & 30.753 & 57.416 & $8^{l}$ & $3.6 m_{b}$ & 15 & 1.6 & 2.6 & 12.8 \\
\hline 2017.12.01 & 05:41:02.7 & 30.717 & 57.366 & $8^{l}$ & $3.7 m_{b}$ & 31 & 1.7 & 2.5 & 12.8 \\
\hline 2017.12.01 & $07: 29: 33.2$ & 30.714 & 57.346 & $12^{l}$ & $3.9 m_{b}$ & 15 & 1.2 & 1.8 & 6.7 \\
\hline 2017.12.01 & $07: 32: 32.5$ & 30.756 & 57.377 & $7^{l}$ & $3.8 m_{b}$ & 19 & 1.7 & 2.6 & 14.4 \\
\hline 2017.12.02 & 05:50:55.6 & 30.754 & 57.399 & $11^{l}$ & $3.8 m_{b}$ & 11 & 1.2 & 1.9 & 7.3 \\
\hline 2017.12.02 & $10: 47: 01.6$ & 30.756 & 57.372 & $7^{l}$ & $5.1 \mathrm{Mw}$ & 355 & 1.1 & 1.5 & 4.8 \\
\hline 2017.12.02 & $16: 41: 17.1$ & 30.714 & 57.411 & $8^{l}$ & $3.8 m_{b}$ & 24 & 1.7 & 2.4 & 12.6 \\
\hline 2017.12.02 & 20:59:22.2 & 30.799 & 57.311 & $10^{l}$ & $3.9 m_{b}$ & 7 & 1.1 & 1.7 & 5.8 \\
\hline 2017.12.03 & $02: 47: 24.8$ & 30.778 & 57.304 & $10^{l}$ & $3.8 m_{b}$ & 5 & 1.2 & 1.9 & 7.2 \\
\hline 2017.12.04 & 02:58:42.9 & 30.729 & 57.389 & $9^{l}$ & $3.8 m_{b}$ & 8 & 1.0 & 1.5 & 4.9 \\
\hline 2017.12.05 & $09: 23: 42.3$ & 30.807 & 57.308 & $7^{l}$ & $3.8 m_{b}$ & 8 & 1.0 & 1.5 & 5 \\
\hline 2017.12.06 & 01:29:50.7 & 30.810 & 57.362 & $10^{l}$ & $3.7 m_{b}$ & 10 & 1.2 & 1.8 & 6.7 \\
\hline 2017.12.06 & $17: 26: 03.2$ & 30.770 & 57.315 & $9^{l}$ & $3.9 m_{b}$ & 15 & 1.2 & 1.7 & 6.2 \\
\hline 2017.12.08 & $12: 38: 28.3$ & 30.790 & 57.350 & $10^{l}$ & $4 m_{b}$ & 9 & 1.2 & 1.6 & 6.2 \\
\hline 2017.12.09 & $07: 42: 58.9$ & 30.794 & 57.392 & $10^{l}$ & $3.9 m_{b}$ & 5 & 1.2 & 1.7 & 6.3 \\
\hline 2017.12.12 & 08:43:16.6 & 30.742 & 57.301 & $14^{l}$ & $5.9 M_{w}$ & 354 & 0.8 & 1.3 & 3.3 \\
\hline 2017.12.12 & $09: 42: 21.6$ & 30.805 & 57.281 & $11^{l}$ & $3.8 m_{b}$ & 3 & 1.1 & 1.6 & 5.4 \\
\hline 2017.12 .12 & 09:50:27.9 & 30.787 & 57.322 & $8^{l}$ & $3.8 m_{b}$ & 9 & 1.1 & 1.6 & 5.5 \\
\hline 2017.12.12 & $10: 26: 25.3$ & 30.731 & 57.336 & $10^{l}$ & $3.6 m_{b}$ & 10 & 1.2 & 1.7 & 6.3 \\
\hline 2017.12.12 & $13: 22: 38.2$ & 30.814 & 57.267 & $10^{l}$ & $4 m_{b}$ & 10 & 1.5 & 2.2 & 10.4 \\
\hline
\end{tabular}


Table S1 (Continued)

\begin{tabular}{|c|c|c|c|c|c|c|c|c|c|}
\hline Date & Time & Lat. & Lon. & Depth & Mag. & A1 & L1 & L2 & Area \\
\hline 2017.12.12 & $16: 50: 19.1$ & 30.809 & 57.306 & $9^{l}$ & $4 m_{b}$ & 7 & 1.1 & 1.5 & 5.1 \\
\hline 2017.12.12 & 21:41:29.5 & 30.822 & 57.279 & $10^{l}$ & 6.1 $M_{w}$ & 353 & 0.8 & 1.3 & 3.3 \\
\hline 2017.12.12 & $21: 55: 44.3$ & 30.754 & 57.337 & $9^{l}$ & $3.9 m_{b}$ & 13 & 1.2 & 1.8 & 7 \\
\hline 2017.12.12 & $22: 36: 02.7$ & 30.809 & 57.310 & $9^{l}$ & $3.9 m_{b}$ & 6 & 1.0 & 1.6 & 5.1 \\
\hline 2017.12.12 & $23: 27: 35.0$ & 30.772 & 57.302 & $8^{l}$ & $4.2 m_{b}$ & 0 & 1.0 & 1.5 & 4.9 \\
\hline 2017.12.13 & 00:07:59.9 & 30.836 & 57.314 & $9^{l}$ & $3.8 m_{b}$ & 358 & 1.0 & 1.4 & 4.4 \\
\hline 2017.12.13 & 04:03:14.3 & 30.841 & 57.290 & $10^{l}$ & $4.1 m_{b}$ & 6 & 1.0 & 1.5 & 4.6 \\
\hline 2017.12.13 & 09:51:54.8 & 30.811 & 57.297 & $10^{l}$ & $4.2 m_{b}$ & 5 & 1.1 & 1.6 & 5.6 \\
\hline 2017.12.15 & 22:01:09.7 & 30.811 & 57.324 & $9^{l}$ & $3.7 m_{b}$ & 7 & 1.2 & 1.7 & 6.3 \\
\hline 2017.12.16 & 02:20:29.6 & 30.800 & 57.290 & $11^{l}$ & $4.3 m_{b}$ & 4 & 1.0 & 1.4 & 4.4 \\
\hline 2017.12.16 & $10: 26: 54.4$ & 30.808 & 57.214 & $10^{l}$ & $3.7 m_{b}$ & 12 & 1.3 & 2.0 & 8.3 \\
\hline 2017.12.19 & $13: 02: 31.1$ & 30.808 & 57.285 & $11^{l}$ & $4 m_{b}$ & 18 & 1.4 & 2.2 & 9.6 \\
\hline 2017.12.22 & $10: 20: 41.3$ & 30.779 & 57.272 & $10^{l}$ & $3.6 m_{b}$ & 14 & 1.5 & 2.3 & 11 \\
\hline 2017.12.23 & $18: 32: 38.0$ & 30.780 & 57.247 & $11^{l}$ & $3.7 m_{b}$ & 6 & 1.0 & 1.6 & 5.2 \\
\hline 2017.12.25 & 03:34:15.2 & 30.790 & 57.387 & $10^{l}$ & $3.7 m_{b}$ & 9 & 1.2 & 1.8 & 6.8 \\
\hline 2017.12.27 & 18:01:13.3 & 30.803 & 57.218 & $10^{l}$ & $5 m_{b}$ & 355 & 0.9 & 1.4 & 3.9 \\
\hline 2018.01 .03 & $04: 13: 10.3$ & 30.725 & 57.369 & $10^{l}$ & $4.2 m_{b}$ & 4 & 1.1 & 1.5 & 4.8 \\
\hline 2018.01.08 & $23: 17: 34.9$ & 30.851 & 57.335 & $9^{l}$ & $3.7 m_{b}$ & 21 & 1.3 & 1.8 & 7.4 \\
\hline 2018.01.10 & $17: 10: 53.1$ & 30.782 & 57.403 & $10^{l}$ & $3.8 m_{b}$ & 6 & 1.1 & 1.6 & 5.6 \\
\hline 2018.01.11 & $03: 18: 28.4$ & 30.729 & 57.362 & $11^{l}$ & $4.7 m_{b}$ & 357 & 1.0 & 1.4 & 4.5 \\
\hline 2018.01.11 & $13: 35: 32.4$ & 30.814 & 57.295 & $10^{l}$ & $4.5 m_{b}$ & 3 & 1.4 & 1.9 & 8.2 \\
\hline 2018.01.12 & 03:03:33.5 & 30.725 & 57.380 & $10^{l}$ & $3.9 m_{b}$ & 4 & 1.3 & 1.8 & 7.1 \\
\hline
\end{tabular}

